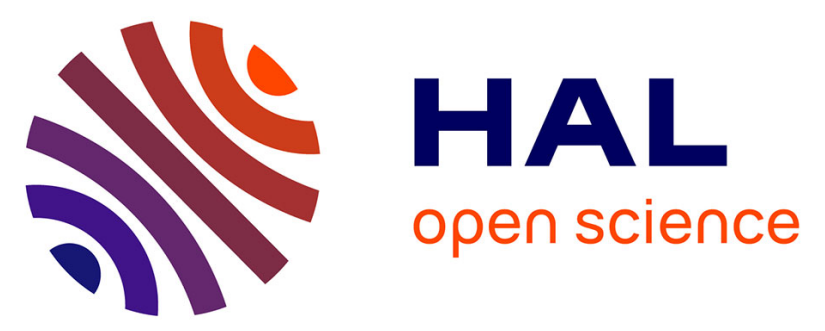

\title{
Characterization of the regions involved in the calcium-induced folding of the intrinsically disordered RTX motifs from the bordetella pertussis adenylate cyclase toxin.
}

\author{
Ana-Cristina Sotomayor Pérez, Johanna C Karst, Marilyne Davi, J Iñaki \\ Guijarro, Daniel Ladant, Alexandre Chenal
}

\section{To cite this version:}

Ana-Cristina Sotomayor Pérez, Johanna C Karst, Marilyne Davi, J Iñaki Guijarro, Daniel Ladant, et al.. Characterization of the regions involved in the calcium-induced folding of the intrinsically disordered RTX motifs from the bordetella pertussis adenylate cyclase toxin.. Journal of Molecular Biology, 2010, 397 (2), pp.534-49. 10.1016/j.jmb.2010.01.031 . hal-00512116

\author{
HAL Id: hal-00512116 \\ https://hal.science/hal-00512116
}

Submitted on 17 Apr 2018

HAL is a multi-disciplinary open access archive for the deposit and dissemination of scientific research documents, whether they are published or not. The documents may come from teaching and research institutions in France or abroad, or from public or private research centers.
L'archive ouverte pluridisciplinaire HAL, est destinée au dépôt et à la diffusion de documents scientifiques de niveau recherche, publiés ou non, émanant des établissements d'enseignement et de recherche français ou étrangers, des laboratoires publics ou privés. 
Characterization of the regions involved in the calcium-induced folding of the intrinsically disordered RTX motifs from the Bordetella pertussis adenylate cyclase toxin

Ana-Cristina Sotomayor Pérez ${ }^{1}$, Johanna C. Karst $^{1}$, Marilyne Davi ${ }^{1}$, J. Iñaki Guijarro ${ }^{2}$, Daniel Ladant $^{* 1}$ and Alexandre Chenal ${ }^{* 1}$

${ }^{1}$ Institut Pasteur, CNRS URA 2185, Unité de Biochimie des Interactions Macromoléculaires, Département de Biologie Structurale et Chimie, 28 rue du Dr Roux, 75724 Paris cedex 15, France;

${ }^{2}$ Institut Pasteur, CNRS URA 2185, Unité de RMN des Biomolécules, Département de Biologie Structurale et Chimie, 28 rue du Dr Roux, 75724 Paris cedex 15, France.

\section{* Corresponding authors}

Alexandre Chenal, Unité de Biochimie des Interactions Macromoléculaires, CNRS URA 2185, Institut Pasteur, 28 rue du Dr. Roux, 75724 Paris cedex 15, France. Tel: 331443892 12; Fax: 331406130 42; email: alexandre.chenal@pasteur.fr; or Daniel Ladant, Unité de Biochimie des Interactions Macromoléculaires, CNRS URA 2185, Institut Pasteur, 28 rue du Dr. Roux, 75724 Paris cedex 15, France. Tel: 331456884 00; Fax: 331406130 42; email: daniel.ladant@pasteur.fr

Running title: Calcium-induced folding of disordered RTX motifs

This article contains Supplementary Material 


\section{Abstract}

Repeat in ToXin (RTX) motifs are nonapeptide sequences found among numerous virulence factors of Gram-negative bacteria. In the presence of calcium, these RTX motifs are able to fold into an idiosyncratic structure called the parallel $\beta$-roll. The adenylate cyclase toxin (CyaA) produced by Bordetella pertussis, the causative agent of whooping cough, is one of the best-characterized RTX cytolysins. CyaA contains a C-terminal receptor domain (RD) that mediates toxin binding to the eukaryotic cell receptor. RD is composed of about 40 RTX motifs organized in 5 successive blocks (called I to V). The RTX blocks are separated by nonRTX flanking regions of variable lengths. It has been shown that the block V with its $\mathrm{N}$ - and C-terminal flanking regions, constitutes an autonomous subdomain required for the toxicity of CyaA. Here, we investigated the calcium-induced biophysical changes of this subdomain to identify the respective contributions of the flanking regions to the folding process of the RTX motifs. We showed that the RTX polypeptides, in the absence of calcium, exhibited the hallmarks of intrinsically disordered proteins and that the C-terminal flanking region was critical for the calcium-dependent folding of the RTX polypeptides, while the N-terminal flanking region was not involved. Furthermore, the secondary and tertiary structures were acquired concomitantly upon cooperative binding of several calcium ions. This suggests that the RTX polypeptide folding is a two-state reaction, from a calcium-free unfolded state to a folded and compact conformation in which the calcium-bound RTX motifs adopt a $\beta$-roll structure. The relevance of these results to the toxin physiology, in particular to its secretion, is discussed.

Keywords: adenylate cyclase CyaA toxin, intrinsically disordered proteins, Repeat in ToXin (RTX), calcium binding proteins, calcium-induced protein folding 


\section{Introduction}

The adenylate cyclase toxin (CyaA) is one of the major virulence factors of Bordetella pertussis, the causative agent of whooping cough ${ }^{1 ; 2}$. CyaA is secreted by virulent bacteria through a dedicated type I secretion system (T1SS, made of the B. pertussis CyaB, CyaD and CyaE proteins) and is able to invade eukaryotic cells ${ }^{4 ; 5 ; 6}$. CyaA is a 1706 residue-long bifunctional protein that exhibits both invasive adenylate cyclase (cytotoxic) and haemolytic (pore-forming) activities on a variety of cell types $4 ; 5 ; 6 ; 7 ; 8$. CyaA shows a unique mechanism of penetration into host cells: after binding to a specific receptor, the CD11b/CD18 integrin, at the surface of target cells ${ }^{9 ; 10}$, the CyaA catalytic domain is translocated directly across their plasma membrane, from the extracellular milieu into the host cell cytoplasm ${ }^{11}$. Inside the cell, CyaA binds calmodulin that stimulates $\sim 1000$ fold its enzymatic activity to produce supraphysiological levels of cAMP $5 ; 6 ; 7 ; 8 ; 1213$, thus altering the cell physiology and leading to cell death by apoptosis $14 ; 15$. The toxin is schematically composed of three functional domains: the calmodulin-activated catalytic domain (adenylate cyclase, residues 1-400), the hydrophobic domain (400-1000) that inserts into the plasma membrane of target cells and the receptor binding domain ( $\mathrm{RD}, 1000-1706)$ that is involved in the interaction with the CD11b/CD18 integrin receptor ${ }^{10}$.

RD is composed of about 40 copies of Repeat in ToXin (RTX) motifs ${ }^{16 ; 17}$ that are involved in binding of calcium, an essential cofactor for CyaA binding to the CD11b/CD18 receptor as well as for its translocation into the target cell cytosol 18; 19;20;21;22; 23 . RTX motifs are characteristic of a large family of bacterial toxins, called cytolysins, which cover a large panel of functions ${ }^{24}$. The members of this family of bacterial toxins share two main characteristics: these are secreted through the T1SS and require the binding of calcium to exert their toxicity 25; 26; 27; 28; 29; 30; 31 The RTX motifs are present in a tandem manner, upstream to the C-terminal secretion signal of the toxins $24 ; 26 ; 32$. A RTX motif is a characteristic glycine and aspartate 
nonapeptide sequence of the prototype GGXGXDXUX, where X represents any amino acid, and $U$ represents any aliphatic or aromatic residue such as Leu, Ile, Val, Phe and Tyr 16;17; 24. Three-dimensional structures of proteins containing RTX motifs showed that consecutive RTX nonapeptides fold into a parallel $\beta$-roll, which consists of two facing sheets of parallel $\beta$ strands linked by calcium-loaded turns ${ }^{33 ; 34 ; 35}$. A turn is made by the first six amino acids GGXGXD from the RTX motif, while the last three residues XUX of the RTX motifs are involved in the formation of $\beta$-strands. The conserved hydrophobic $U$ residue of the XUX motif stabilizes the hydrophobic core of the $\beta$-roll structure. The stacking of consecutive turns and $\beta$-strands builds up a right-handed helix of parallel $\beta$-strands; one turn of this helix consisting in two consecutive RTX motifs. Calcium is hexacoordinated between two spatially adjacent turns by the conserved aspartic acids and by backbone carbonyls ${ }^{33}$.

Recently, we demonstrated by various biophysical approaches that, at low calcium concentrations (similar to those prevailing in the bacterial cytosol), RD displays characteristic features of intrinsically disordered proteins $36 ; 37 ; 38 ; 39 ; 40$, while in the presence of $\mathrm{mM}$ concentrations of calcium (like those found in the extracellular medium), RD acquires a stable $\beta$-rich conformation ${ }^{41}$. We proposed that the intrinsically disordered character of the calciumfree protein (apo form) may facilitate its secretion through the T1SS, while calcium binding could trigger folding of RD in the extracellular medium ${ }^{41}$.

RD of CyaA is organized in 5 successive blocks (I to V) of 8-10 RTX motifs separated by linkers of variable lengths (from 23 to 49 residues) ${ }^{18 ; 42}$. Prior studies have shown that the last 217 C-terminal residues of CyaA constitute an autonomous subdomain that can complement inactive forms of CyaA truncated at their C-terminus ${ }^{19 ; 22}$. This region (residues 1490-1706) encompasses the 9 RTX motifs of block V as well as non-RTX N- and C-terminal flanking Sequences ${ }^{18 ; 19 ; 22}$. 
Biochemical and biophysical characterization of this polypeptide indicated that it was able to bind up to 6-7 calcium ions per molecule with an affinity in the millimolar range and that calcium binding induced large changes in its secondary structure ${ }^{18}$. In addition, it has been shown that a shorter polypeptide containing only the RTX motifs of block V was unable to bind calcium and its secondary structure was not affected by addition of calcium ${ }^{18}$. This suggested that the segments adjacent to the RTX repeat motifs of block V are essential for calcium binding and protein folding.

Here, we have characterized the role of these flanking regions in the calcium-induced folding of the RTX motifs. We showed that the C-terminal proximal region was critical for the calcium-dependent formation of the $\beta$-roll structure while the $\mathrm{N}$-terminal region remained largely unstructured. These findings have direct implications for the folding of RTX polypeptides and the physiology of CyaA. 


\section{Results}

To gain insight into the calcium-induced folding of the RTX motifs and the role of the flanking regions in this process, we produced and characterized 6 different polypeptides that contain the 9 RTX motifs of block V but differ in the presence and/or length of the flanking regions at either the $\mathrm{N}$ - or the $\mathrm{C}$-terminal ends of the RTX sequences. According to secondary structure predictions and previous data, the primary sequence of block V of CyaA (residues 1487 to 1680 ) was separated into 4 distinct regions as illustrated in Fig. 1 (the very Cterminus of CyaA, i.e., residues 1683 to 1706 , contains a secretion signal but is not implicated in CyaA cytotoxicity ${ }^{4 ; 19 ; 43}$ ).

The $\mathrm{R}$ region encompasses CyaA residues 1530 to 1630 comprising the 9 RTX motifs of block V. The N-terminal flanking region, called N, ranges from residues 1487 to 1529 , while the C-terminal region was subdivided into two distinct segments, based on secondary structure prediction: a short one, $\mathrm{C}_{\mathrm{S}}$, corresponding to the residues proximal to the RTX motifs (i.e., residues 1631-1652) and a long extension, $\mathrm{C}_{\mathrm{L}}$, encompassing residues 1631-1680. The distal part of $C_{L}$ (i.e. residues 1653-1680) is predicted to adopt $\alpha$ helical conformations while the proximal part (i.e. $\mathrm{C}_{S}$ ) is predicted to be mainly unordered. The 6 polypeptides, designated as $\mathrm{NRC}_{\mathrm{L}}, \mathrm{NRC}_{\mathrm{S}}, \mathrm{NR}, \mathrm{RC}_{\mathrm{L}}, \mathrm{RC}_{\mathrm{S}}$, and $\mathrm{R}$ (Fig. 1) were over-produced in E. coli and purified to homogeneity (as determined by SDS-PAGE, N-terminal sequencing and mass spectrometry; see Material and methods for details).

\section{Tryptophan fluorescence spectroscopy}

To identify the regions that are important for calcium-induced conformational changes, we first studied the tryptophan intrinsic fluorescence of the 6 polypeptides as a function of calcium concentration. All these polypeptides contain at least 1 tryptophan located at position 
1621 in the $\mathrm{R}$ region while those containing the $\mathrm{C}$-terminal extensions $\mathrm{C}_{\mathrm{S}}$ or $\mathrm{C}_{\mathrm{L}}$ possess a second tryptophan at position 1645 .

In the absence of calcium, the maximum wavelength emission $\left(\lambda_{\max }\right)$ of the polypeptides was around $354 \mathrm{~nm}$ (Table 1), indicating that the tryptophans in the apo-state (i.e., in the absence of calcium) were highly exposed to the solvent. Upon addition of calcium, an increase in the fluorescence intensities as well as a blue shift of the $\lambda_{\max }$ (Table 1 and Fig. S1) was observed for all polypeptides harboring the C-terminal extension $\mathrm{C}_{\mathrm{S}}$ or $\mathrm{C}_{\mathrm{L}}$ (i.e., $\mathrm{NRC}_{\mathrm{L}}, \mathrm{NRC}_{\mathrm{S}}, \mathrm{RC}_{\mathrm{L}}$, and $\mathrm{RC}_{\mathrm{S}}$ ). In contrast, the tryptophan fluorescence emission spectra of the NR and $\mathrm{R}$ polypeptides were not affected by the addition of calcium, even in the presence of concentrations up to $100 \mathrm{mM}$. This suggested that, either the fluorescence of the unique tryptophan 1621 of the NR and R polypeptides was not affected by calcium-induced conformational changes or, alternatively, that these polypeptides were unable to bind calcium in these conditions. Indeed, calcium-binding assays confirmed that, while $\mathrm{NRC}_{\mathrm{L}}, \mathrm{RC}_{\mathrm{L}}$ and $\mathrm{RC}_{\mathrm{S}}$ were able to bind calcium ions, the R polypeptide was not (Fig. S2).

The calcium binding properties of $\mathrm{NRC}_{\mathrm{L}}, \mathrm{NRC}_{\mathrm{S}}, \mathrm{RC}_{\mathrm{L}}$, and $\mathrm{RC}_{\mathrm{S}}$ polypeptides were further characterized by following the conformational changes induced by the addition of calcium determined by the ratio of the fluorescence intensities emitted at $360 \mathrm{~nm}$ and $320 \mathrm{~nm}$ $\left(\mathrm{FIR}_{360 / 320}\right)$. As shown in Fig. 2 and Table $1, \mathrm{NRC}_{\mathrm{L}}$ and $\mathrm{RC}_{\mathrm{L}}$, bound calcium with very similar affinities (apparent $K_{D}{ }^{\mathrm{Ca}^{2+}}$ of $\sim 0.5 \mathrm{mM}$ ). $\mathrm{NRC}_{\mathrm{S}}$ and $\mathrm{RC}_{\mathrm{S}}$ exhibited similar calcium affinities that were, however, significantly lower $\left(K_{D}{ }^{C a^{2+}} \sim 3.5 \mathrm{mM}\right.$, see Table 1$)$, as compared to $\mathrm{NRC}_{\mathrm{L}}$ and $\mathrm{RC}_{\mathrm{L}}$. At a lower salt concentration $(20 \mathrm{mM} \mathrm{NaCl}$ instead of $100 \mathrm{mM})$, the 
relative affinities of the polypeptides for calcium increased (see Table 1), revealing a competition effect of sodium for calcium binding sites. Finally, a Hill number $\left(\mathrm{n}_{\mathrm{H}}\right)$ higher than 4 was found for all these polypeptides, indicating that the calcium-induced transition from the apo-state to the holo-state (i.e., the calcium-loaded state) was a highly cooperative process.

In summary, these data indicate that the affinity of the polypeptides for calcium was mainly modulated by the length of the $\mathrm{C}$-terminal flanking sequence, and that the $\mathrm{N}$-terminal segment did not contribute significantly to the calcium binding process.

\section{Far-UV circular dichroism spectroscopy}

The calcium-induced secondary structural changes of the polypeptides were investigated by circular dichroism (CD) in the far-UV region. In the absence of calcium, the far-UV CD spectra of the 6 polypeptides were typical of disordered proteins (Fig. 3) as indicated by the

strong negative $\pi_{0}-\pi^{*}$ band around $200 \mathrm{~nm}^{44 ; 45}$. Nevertheless, a weak negative $\mathrm{n}^{\prime}-\pi^{*}$ band around $220 \mathrm{~nm}$ suggested the presence of some residual secondary structure in the apo-state of these polypeptides.

The far-UV CD spectra of the NR and R polypeptides were not affected by the addition of up to $20 \mathrm{mM}$ calcium (Fig. 3d for R, data not shown for NR). This confirms our prior results on $\mathrm{R}^{18}$, and suggests that the presence of the $\mathrm{N}$ terminal flanking region is not sufficient to induce the folding of the RTX motifs. In contrast, the polypeptides with a C-terminal extension (either the short $\mathrm{C}_{\mathrm{S}}$ or the long $\mathrm{C}_{\mathrm{L}}$ segment), exhibited large changes in their farUV CD spectra upon calcium addition, with a concomitant intensity increase of the n'- $\pi^{*}$ band and a decrease of the negative $\pi_{0}-\pi^{*}$ band (Fig. 3a-c). This indicates an acquisition of secondary structures at the expense of unordered conformations. Taken together, these data show that the polypeptide region at the C-terminus of the RTX motifs (either the short $\mathrm{C}_{\mathrm{S}}$ or 
the long $\mathrm{C}_{\mathrm{L}}$ segment) was essential for calcium-induced formation of RTX secondary structures while the N-terminal region was not involved.

Calcium titration of the different polypeptides was performed to further characterize the secondary structure changes and determine the relative affinity of each polypeptide (Fig. 4 and Table 2). Fig. 4a illustrates the far-UV CD spectra of $\mathrm{RC}_{\mathrm{L}}$ at various $\mathrm{CaCl}_{2}$ concentrations ranging from 0 to $10 \mathrm{mM}$ while Fig. $4 \mathrm{~b}$ shows the changes of the ellipticity at $218 \mathrm{~nm}$ as a function of calcium concentration for the $\mathrm{NRC}_{\mathrm{L}}, \mathrm{RC}_{\mathrm{L}}, \mathrm{RC}_{\mathrm{S}}$, and $\mathrm{R}$ polypeptides. While the $\mathrm{N}$ terminal segment did not affect the $K_{D}{ }^{C a^{2+}}$ of the polypeptides (compare $\mathrm{NRC}_{\mathrm{L}}$ to $\mathrm{RC}_{\mathrm{L}}$ for instance), the length of the C-terminal flanking region drastically influenced the calcium concentration required to induce secondary structure formation. Indeed, the affinity of the $\mathrm{NRC}_{\mathrm{L}}$ or $\mathrm{RC}_{\mathrm{L}}$ polypeptides (with the long C-terminal flanking region) was higher than that of $\mathrm{NRC}_{\mathrm{S}}$ or $\mathrm{RC}_{\mathrm{S}}$ (with the short C-terminal extension) (Fig. 4b). It is noteworthy that at a lower salt concentration $(20 \mathrm{mM} \mathrm{NaCl}$ instead of $100 \mathrm{mM})$, the affinity of $\mathrm{RC}_{\mathrm{S}}$ for calcium was increased by approximately one order of magnitude, in agreement with the fluorescence studies (see above). Hence, the proximal C-terminal flanking region appeared to be sufficient for calcium-induced secondary structure formation, although the folding of $\mathrm{RC}_{\mathrm{S}}$ required higher calcium concentrations than $\mathrm{RC}_{\mathrm{L}}$. Importantly, the absence of the $\mathrm{C}$-terminal flanking region totally abolished the calcium-induced secondary structure folding of the RTX polypeptides (Figs. $4 \mathrm{~b}$ and $3 \mathrm{~d}$ ). We then checked that both, the C-terminal $\mathrm{C}_{\mathrm{S}}$ peptide on one hand, and an equimolar mixture of $\mathrm{R}$ and $\mathrm{C}_{\mathrm{L}}$ on the other hand (obtained by site-specific proteolysis with factor $\mathrm{Xa}$ of $\mathrm{RC}_{\mathrm{LXa}}, \mathrm{a} \mathrm{RC}_{\mathrm{L}}$ variant in which Ile1631 was converted by sitedirected mutagenesis to a Gly residue, creating a unique factor Xa cleavage site) remained unfolded upon calcium addition (Figs. S3-S5 and see Material and Methods section for details). This indicates that the secondary and tertiary structure content of both isolated C- 
terminal flanking regions $\mathrm{C}_{\mathrm{S}}$ and $\mathrm{C}_{\mathrm{L}}$ is unaffected by calcium addition. Taken together, these data show that the RTX motifs and the C-terminal flanking region must belong to the same polypeptide to undergo the calcium-induced conformational change.

Interestingly, the calcium-dependent folding of the RTX polypeptides containing the Cterminal flanking regions showed a strong cooperativity, as revealed by the high $\mathrm{n}_{\mathrm{H}}$ values $(\sim$ 5, Fig. $4 \mathrm{~b}$ and Table 2). This indicates that the formation of the secondary structure requires the simultaneous binding of several calcium ions per RTX polypeptides. Finally, the selectivity of the RTX polypeptides for divalent cations was also investigated and we found that among the various cations tested $\left(\mathrm{CaCl}_{2}, \mathrm{MgCl}_{2}, \mathrm{MnCl}_{2}, \mathrm{SrCl}_{2}, \mathrm{ZnCl}_{2}, \mathrm{CoCl}_{2}, \mathrm{RbCl}_{2}\right.$ or $\mathrm{NiCl}_{2}$ ), only $\mathrm{CaCl}_{2}$ induced conformational changes (Fig. S6).

To better identify the type of secondary structure acquired by $\mathrm{NRC}_{\mathrm{L}}, \mathrm{RC}_{\mathrm{L}}$ and $\mathrm{RC}_{\mathrm{S}}$ upon calcium binding, the far-UV CD spectrum of the apo-state was subtracted from the spectrum of the holo-state of each polypeptide (Fig. 4c). The resulting spectra clearly showed the acquisition of an $n^{\prime}-\pi^{*}$ band with a $\lambda_{\max }$ centered at $218 \mathrm{~nm}$. Interestingly, these differential spectra did not fit well to the canonical far-UV CD spectra of regular secondary structures, although the overall shape of the far-UV CD spectra presented in Fig. 4c corresponded rather to $\beta$-conformations (see Discussion).

To estimate the individual contribution of the $\mathrm{N}$ - and $\mathrm{C}$-terminal flanking sequences to the secondary structure formation, the spectra of the different polypeptides were compared after converting the far-UV CD spectra into molecular ellipticity units (and thus allowing comparison between proteins of different lengths, see Fig. S7). Fig. 5a shows the difference spectrum of the holo-state minus the apo-state for the $\mathrm{NRC}_{\mathrm{L}}$ and $\mathrm{RC}_{\mathrm{L}}$ polypeptides. The spectra are very similar and display comparable positive $\pi_{0}-\pi^{*}$ bands $\left([\theta] \approx+1510^{5}\right.$ 
deg.dmol $\left.{ }^{-1} \cdot \mathrm{cm}^{2}\right)$ and negative $\mathrm{n}^{\prime}-\pi^{*}$ bands $\left([\theta] \approx-610^{5}\right.$ deg. $\left.\mathrm{dmol}^{-1} \cdot \mathrm{cm}^{2}\right)$, indicating that the secondary structure changes induced by calcium binding were very similar in $\mathrm{NRC}_{\mathrm{L}}$ and $\mathrm{RC}_{\mathrm{L}}$ (Fig. 5a). This suggests that the overall number of amino-acids involved in the formation of the calcium-induced secondary structures was comparable in both polypeptides, and therefore, that the $\mathrm{N}$-terminal extension in $\mathrm{NRC}_{\mathrm{L}}$ did not significantly contribute to this change. This was confirmed by the difference spectra between the two polypeptides $\mathrm{NRC}_{\mathrm{L}}$ and $\mathrm{RC}_{\mathrm{L}}$ either in their apo- or holo-state. In both cases, the spectra ("apo- $\mathrm{NRC}_{\mathrm{L}}$ minus apo- $\mathrm{RC}_{\mathrm{L}}$ " or "holo$\mathrm{NRC}_{\mathrm{L}}$ minus holo- $\mathrm{RC}_{\mathrm{L}}$ ") exhibited a strong negative $\pi_{0^{-}} \pi^{*}$ band, typical of random coils (Fig. $5 b)$. This suggests that the $\mathrm{N}$ region adopts a disordered conformation both in the absence and in the presence of calcium.

A similar analysis was carried out by comparing the $\mathrm{CD}$ spectra of $\mathrm{RC}_{\mathrm{L}}$ and $\mathrm{RC}_{\mathrm{S}}$ with the aim of estimating the contribution of the distal C-terminal flanking region to the secondary structure content (Fig. 5c). The difference spectrum between $\mathrm{RC}_{\mathrm{L}}$ and $\mathrm{RC}_{\mathrm{S}}$ in their apo-state (apo- $\mathrm{RC}_{\mathrm{L}}$ minus apo- $\mathrm{RC}_{\mathrm{S}}$ ) was indicative of a low secondary structure content. The difference spectrum between $\mathrm{RC}_{\mathrm{L}}$ and $\mathrm{RC}_{\mathrm{S}}$ in their holo-state, however, was characteristic of $\alpha$-helical structures. These data suggest that the C-terminal distal region contributed to an overall increase in $\alpha$-helical content of the RTX polypeptides upon calcium binding.

\section{Near-UV circular dichroism spectroscopy}

The tertiary structure content of the polypeptides was followed by near-UV CD spectroscopy. The near-UV CD spectra of the apo-state of the R polypeptide indicated the absence of a tertiary structure involving its aromatic side-chains (Fig. 6a). Similar spectra were obtained for the $\mathrm{NR}, \mathrm{RC}_{\mathrm{S}}$, and $\mathrm{NRC}_{\mathrm{S}}$ polypeptides (data not shown). However, the near-UV CD spectra of the apo-states of $\mathrm{RC}_{\mathrm{L}}$ (Fig. 6b) and $\mathrm{NRC}_{\mathrm{L}}$ (Fig. 6c) showed a more pronounced spectral shape with a small but broad negative band, indicating the presence of residual tertiary 
structure elements involving tyrosine and/or tryptophan side chains. As the fluorescence results suggested that the tryptophans in the apo-proteins were exposed to the solvent (Fig. 2 and Table 1), the near-UV CD signals (Figs. $6 \mathrm{~b}$ and c) could mainly arise from tyrosine sidechains.

The addition of calcium did not affect the near-UV CD spectra of R (Fig. 6a) and NR (data not shown). The near-UV CD spectrum of the holo-state of $\mathrm{RC}_{\mathrm{L}}$ (Fig. 6b) and $\mathrm{NRC}_{\mathrm{L}}$ (Fig. 6c) revealed that calcium binding induced significant changes in their tertiary structures. The near-UV CD bands located at 265 and $271 \mathrm{~nm}$ are typical of the weak, negative and wellresolved vibronic bands from phenylalanine $L_{b}$ state. The vibrational fine structures observed in the near-UV region ranging from 275 to $282 \mathrm{~nm}$ may be assigned to overlapping tyrosine $\mathrm{L}_{\mathrm{b}}$ bands and tryptophan $\mathrm{L}_{\mathrm{a}}$ bands. The last band located at $291 \mathrm{~nm}$ is characteristic of a tryptophan $\mathrm{L}_{\mathrm{b}}$ state ${ }^{44 ; 45}$. Taken together, such near-UV CD spectra revealed that several aromatic residues were involved in the formation and stabilization of the tertiary structure of the holo-state of these RTX polypeptides.

The contribution of the N-terminal flanking region to the tertiary structure was assessed by the comparison of the near-UV CD spectra of $\mathrm{RC}_{\mathrm{L}}$ (Fig. 6b) and $\mathrm{NRC}_{\mathrm{L}}$ (Fig. 6c). The corresponding spectra of both polypeptides were similar in the apo-state and in the holo-state, suggesting again that the $\mathrm{N}$ region was not involved in calcium-induced tertiary structural changes. This is in agreement with fluorescence and far-UV CD data showing that $\mathrm{N}$ was mainly disordered in both states. Calcium titrations monitored by near-UV CD were carried out to estimate the $\mathrm{K}_{\mathrm{D}}$ of the calcium-induced tertiary structural changes of $\mathrm{RC}_{\mathrm{L}}$ (Fig. S8). As shown in Fig. 6d, when the calcium-titrations were recorded in both the far-UV and near-UV regions, effectively identical $K_{D}{ }^{\mathrm{Ca}^{2+}}$ values for secondary and tertiary structure changes were found. 
Taken together, these data showed that the main secondary and tertiary structural changes occurred in the same calcium concentration range and that the folding reaction exhibited similar cooperativity (see $\mathrm{n}_{\mathrm{H}}$ in Table 2 and Table $\mathrm{S} 3$ ).

\section{ANS fluorescence}

To determine whether the polypeptides exposed or not some organized hydrophobic clusters to the solvent, we followed the fluorescence of 8-anilino-1-napthalene sulfonic acid (ANS) upon addition of polypeptides and calcium. No change of the ANS fluorescence spectral properties was observed, indicating that none of the polypeptides bound ANS either in the absence or in the presence of calcium (data not shown). Moreover, no fluorescence changes were detected upon calcium titration. Finally, ANS fluorescence was not affected by thermal denaturation of the polypeptides. Taken together, these data indicate the absence of intermediate states exhibiting hydrophobic regions to the solvent during both the calciuminduced folding and the thermal-induced denaturation of the polypeptides.

\section{Acrylamide quenching of tryptophan fluorescence}

Intrinsic fluorescence data suggested that tryptophan side-chains were exposed to the solvent in the apo-state of the polypeptides and became less polar upon calcium binding (Fig. 2). To characterize the solvent accessibility of tryptophans both in the apo- and in the holo-states, we performed collisional quenching of tryptophan fluorescence experiments using acrylamide as quencher ${ }^{46}$. Typical modified-Stern-Volmer plots of tryptophan quenching as a function of acrylamide concentration are shown in Fig. 7 for the apo- and the holo-state of $\mathrm{RC}_{\mathrm{L}}$, for the apo-state of $\mathrm{R}$ and for soluble L-tryptophan.

According to the accessible fraction value of tryptophan fluorescence to acrylamide $(0.99$ 1.05, see Table 3 for details), all tryptophans were solvent-accessible in both apo- and holo- 
states of the various polypeptides. Although all tryptophans were exposed to the quencher in both states, those in the apo-states were more easily accessible than those in the holo-states, as illustrated for $\mathrm{RC}_{\mathrm{L}}$ (see the slopes for $\mathrm{RC}_{\mathrm{L}}$ in Fig. 7 and $\mathrm{K}_{\mathrm{A}}$ values in Table 3). These results suggest that the tryptophans were most probably located near the protein surface in the holostate rather than buried in the protein structure. It is noteworthy that the tryptophan of $\mathrm{R}$, a polypeptide of 111 amino acids, is as accessible to the solvent than the L-tryptophan used as a control. This further illustrates the natively disordered character of the RTX polypeptides in the apo-state.

\section{Calcium-induced hydrodynamic changes}

To characterize the calcium-induced hydrodynamic changes of the RTX polypeptides, a combination of experimental approaches was used to obtain the hydrodynamic parameters of their apo- and holo-states (see Table 4). These studies were focused on the $\mathrm{R}$ and $\mathrm{RC}_{\mathrm{L}}$ polypeptides as examples of calcium-insensitive and calcium-sensitive proteins, respectively. We determined the partial specific volume $(\bar{v})$ by equilibrium analytical ultracentrifugation (AUC), the sedimentation coefficient $(\mathrm{S})$ by velocity AUC, the hydrodynamic radius $\left(\mathrm{R}_{\mathrm{H}}\right)$ by quasi-elastic light scattering (QELS), the molecular mass (M) and the intrinsic viscosity ( $[\eta])$ by size exclusion chromatography coupled on-line to a triple detector array (SEC-TDA, see Material and Methods section for details on the procedures).

We first determined the $\mathrm{R}_{\mathrm{H}}$ of the polypeptides by QELS in the absence or in the presence of calcium. While the $\mathrm{R}_{\mathrm{H}}$ of $\mathrm{R}(2.7 \mathrm{~nm})$ was similar both in the absence and in the presence of calcium, the $\mathrm{R}_{\mathrm{H}}$ of $\mathrm{RC}_{\mathrm{L}}$ decreased from 3.2 to $2.2 \mathrm{~nm}$ upon calcium addition (see Table 4), indicating that calcium binding triggers compaction of the RTX polypeptide having the Cterminal extension. 
We then investigated the polypeptides by SEC-TDA (Fig. 8). The chromatograms in Fig. 8 (a and b) illustrate the behavior of the $\mathrm{RC}_{\mathrm{L}}$ and $\mathrm{R}$ polypeptides on a Superdex 200 column. Apo$\mathrm{RC}_{\mathrm{L}}$ eluted at $18 \mathrm{~mL}$ while holo- $\mathrm{RC}_{\mathrm{L}}$ eluted at $22 \mathrm{~mL}$ (Fig. 8a). This difference of retention volume correlates with the $\mathrm{R}_{\mathrm{H}}$ changes (see Table 4). The differential refractometer signal (RI, black profiles) and the right angle light scattering signals (RALS, green profiles) are similar for both states of $\mathrm{RC}_{\mathrm{L}}$. Consequently, the molecular masses were similar for apo- $\mathrm{RC}_{\mathrm{L}}$ and holo- $\mathrm{RC}_{\mathrm{L}}$, corresponding to a monomer (Fig. 8c, green traces and Table 4). The difference of retention volume between both states arose from their respective intrinsic viscosity, as revealed by the difference between the differential pressure (DP) transducer signals (Fig. 8a, red profiles). Indeed, the intrinsic viscosity of $\mathrm{RC}_{\mathrm{L}}$ strongly decreased (from 13.7 to $3.9 \mathrm{~mL} \cdot \mathrm{g}^{-1}$, Table 4) upon calcium binding (Fig. 8c, red traces).

The retention volume of the $\mathrm{R}$ polypeptide on the Superdex 200 column (Fig. 8b) was identical in the absence and in the presence of $2 \mathrm{mM}$ calcium. Moreover, the RI, RALS and DP signal intensities were similar for both the apo-state (dashed lines) and the holo-state (solid lines). Accordingly, the molecular mass and the intrinsic viscosity of $\mathrm{R}$ were similar in the absence and in the presence of calcium (Fig. 8d and Table 4), in agreement with the absence of $R_{H}$ changes of $R$ upon calcium addition. These results indicate that the $\mathrm{C}$-terminal flanking region is mandatory for the calcium-induced hydrodynamic changes, particularly regarding the $\mathrm{R}_{\mathrm{H}}$ and intrinsic viscosity changes.

The intrinsic viscosity is given by $[\eta]=v(\bar{v}+\delta / \rho)$, which includes the viscosity increment $v$ (a shape factor), the partial specific volume $\bar{v}$, the solvent density $\rho$ and the time-averaged apparent hydration of the polypeptide $\delta$, which consists of the water molecules bound to and entrained by the diffusion of the protein (see ${ }^{47}$ for a review). We aimed to resolve the respective contribution of the viscosity increment and of the hydration parameters from the intrinsic viscosity values obtained for $\mathrm{R}$ and $\mathrm{RC}$. The procedures to calculate the 
hydration and to estimate the gross conformation (the values of the semi-axes a/b of an equivalent ellipsoid) of the proteins are described under the Material and Methods section. The data presented in Table 4 suggested that the hydrodynamic shapes of $\mathrm{R}$ and $\mathrm{RC}_{\mathrm{L}}$ were similar in their apo- and holo-states and could be approximated to spheres or ellipsoids characterized by low axial ratios. Both the $\mathrm{R}$ and $\mathrm{RC}_{\mathrm{L}}$ polypeptides exhibited a high hydration (close to 4.0 g.g ${ }^{-1}$ ) in the apo-state, hydration that was about ten times higher than the theoretical value $\left(0.43 \mathrm{~g} . \mathrm{g}^{-1}\right)$ calculated with the Sednterp software. In the presence of calcium, the hydration of $\mathrm{R}$ was not affected but that of $\mathrm{RC}_{\mathrm{L}}$ was strongly reduced: while the $\mathrm{RC}_{\mathrm{L}}$ hydration was close to $4.3 \mathrm{~g} \cdot \mathrm{g}^{-1}$ in the apo-state, it was below $1 \mathrm{~g} \cdot \mathrm{g}^{-1}$ in the holo-state (Table 4).

Taken together, the hydrodynamic analysis indicated that the main characteristic of the $\mathrm{R}$ and $\mathrm{RC}_{\mathrm{L}}$ polypeptides in the apo-state was their high hydration. This high hydration value is related to the hydrodynamic envelope - the time-averaged excluded volume - in which the highly dynamic polypeptides in the apo-state evolve. Such high hydration values could be a general physico-chemical characteristic shared by other intrinsically disordered RTX polypeptides in the apo-state. The high hydration values observed for the apo-states correlate with the high $\mathrm{R}_{\mathrm{H}}$ and the low $\mathrm{S}$ values: the RTX polypeptides are disordered, loose and hydrated, and such properties slow-down the sedimentation velocities of the molecules. Overall, the data clearly indicate that the presence of the C-terminal flanking region is required to allow a strong dehydration and compaction of the RTX polypeptides upon calcium binding (see the variations of $\mathrm{S}, \mathrm{R}_{\mathrm{H}}$ and $\delta$ values in Table 4). 


\section{Discussion}

The Repeat in Toxin (RTX) motifs are tandemly repeated calcium-binding nonapeptide sequences that fold into a parallel $\beta$-roll and that are found in various cytolysins produced by Gram-negative bacteria. We recently showed that the RTX-containing domain of B. pertussis CyaA is intrinsically disordered in the absence of calcium and adopts a stable and compact fold upon calcium binding ${ }^{41}$. To get a better understanding of the calcium-induced folding of these RTX structures, we have characterized the physico-chemical properties of a subdomain of CyaA (residues 1487 to 1680) that encompasses the last 9 RTX motifs of CyaA (forming the so-called block $\mathrm{V}$ of repeats), that was shown previously to be essential for CyaA toxicity $18 ; 19 ; 22$

In the present work, six recombinant polypeptides of variable lengths, all including the core RTX region of block $\mathrm{V}$ (the $\mathrm{R}$ region), but differing in the presence or absence of the Nterminal and C-terminal flanking regions (see Fig.1), were investigated by a combination of biophysical approaches. The results indicate that all these polypeptides were intrinsically disordered in the absence of calcium: their secondary structure spectra were typical of random coils and their tryptophans were solvent-exposed and fully accessible to quenchers. Moreover, no hydrophobic patches were exposed to the solvent. Accordingly, these RTX polypeptides were highly hydrated and their hydrodynamic radii were higher than the values expected for folded proteins of similar molecular masses (compare for instance the $\mathrm{R}_{\mathrm{H}}$ and $\mathrm{R}_{0}$ of apo- $\mathrm{RC}_{\mathrm{L}}$ and apo-R in Table 4).

We found here that the RTX motifs without the C-terminal flanking region were unable to fold in the presence of calcium (Figs. 2 and 3). In agreement, we showed that only the RTX polypeptides with a C-terminal flanking region were able to bind calcium (Fig. S2). Importantly, our present results provide direct evidence that the C-terminal proximal flanking region, $\mathrm{C}_{\mathrm{S}}$ (residues 1631-1652 of CyaA), was absolutely required to observe a calcium- 
induced folding of the RTX polypeptides (Figs. 2, 3, 6 and 8). Moreover, their calcium titration followed by fluorescence and $\mathrm{CD}$ showed that an additional extension of the Cterminal flanking region up to residue 1680 of CyaA (corresponding to the $\mathrm{C}_{\mathrm{L}}$ region encompassing residues 1631-1680), strongly improved the affinity for calcium. The folding is selectively triggered by calcium binding, as other divalent cations were not able to induce the formation of secondary structures (Fig. S6). The RTX polypeptides with the C-terminal extensions not only acquired secondary and tertiary structures concomitantly upon calcium binding (Figs. 2, 4-6 and Table 1), but also underwent a strong compaction and dehydration (Fig. 8 and Table 4).

Interestingly, an analysis of the Stokes radii - molecular mass dependencies according to Uversky's or Wilkins's approaches ${ }^{48 ; 49 ; 50}$ (Fig. S9) revealed that holo- $\mathrm{RC}_{\mathrm{L}}$ is positioned in between molten globule and native conformations, while the apo-states (apo- $\mathrm{R}$ and apo- $\mathrm{RC}_{\mathrm{L}}$ ) are positioned in between natively unfolded (NU) coil and pre-molten globule (PMG) conformations (Fig. S9). Our present study is therefore in good agreement with this analysis: the apo-state of these RTX polypeptides is mainly unfolded with residual secondary and tertiary structures (Figs. 3 and 6), as expected for NU coil / PMG conformations. Overall, our data indicate that the binding of calcium induces the formation of native globular structure in $\mathrm{RC}_{\mathrm{L}}$ at the expense of disordered conformations.

In addition, far-UV CD data suggested that the C-terminal part of the $\mathrm{C}_{\mathrm{L}}$ segment might adopt an $\alpha$-helical conformation in the folded holo-state (Fig. 5). It is noteworthy that the isolated short C-terminal flanking region (the $\mathrm{C}_{\mathrm{S}}$ peptide) or even an equimolar mixture of the $\mathrm{R}$ and $\mathrm{C}_{\mathrm{L}}$ polypeptides were not able per se to undergo a calcium-induced conformational change (Fig. S3-S5). Taken together, these results suggested that intramolecular tertiary contacts between the $\mathrm{C}_{\mathrm{L}}$ flanking region and the RTX motifs within a single polypeptide chain may be required to form and stabilize the calcium-loaded $\beta$-roll fold. 
On the contrary, the region at the N-terminus of the RTX motifs (N, residues 1487-1529) had no effect on the calcium-dependent folding of the polypeptides and remained mainly unfolded in the absence as well as in the presence of calcium (Fig. 5b). Therefore, the N-terminal region is probably not an integral part of the block $\mathrm{V}$ folding unit but rather could serve as a tether with the upstream block IV of CyaA. Alternatively, the $\mathrm{N}$ region might also be directly involved in the folding of the preceding group of RTX motifs, i.e., the block IV.

At present, it is not known whether each individual group of RTX repeats in CyaA can fold independently of each other or if the calcium-induced folding of the whole RD domain of CyaA follows a sequential process initiated from the block $\mathrm{V}$ subdomain that would serve as a nucleating site. Interestingly, this subdomain was previously shown to complement and bind inactive CyaA proteins lacking the $\mathrm{C}$-terminal end, suggesting specific interdomain interactions between this C-terminal RTX subdomain and the upstream region(s) of CyaA ${ }^{18}$; 19; 22 . Lilie et al. ${ }^{34}$ also showed that a synthetic polypeptide made of several consensus RTX motifs was able to form a $\beta$-roll in the presence of calcium only upon polymerization, indicating that intermolecular interactions were essential to stabilize the $\beta$-roll structure of these synthetic repeats.

An interesting observation was made upon close inspection of the far-UV difference spectra of the polypeptides containing a C-terminal flanking region, $\mathrm{C}_{\mathrm{S}}$ or $\mathrm{C}_{\mathrm{L}}$. These spectra did not fit to the canonical CD spectra of regular secondary structures in the far-UV range ${ }^{44 ; 45}$. Indeed, the $\pi_{0}-\pi^{*}$ band is a unique, non-split band around $200 \mathrm{~nm}$, unlike the $\alpha$-helix $\pi_{0}-\pi^{*}$ band which is characterized by an exciton splitting with positive (below $200 \mathrm{~nm}$ ) and negative (around $208 \mathrm{~nm}$ ) contributions. The overall shape of the far-UV CD spectra (Figs. 4c and 5a) corresponded rather to $\beta$-conformations. However, the polarity of the $n^{\prime}-\pi^{*}$ band $\left(\lambda_{\max }: 218\right.$ $\mathrm{nm}$ ) suggested that the secondary structure elements of the RTX polypeptides were distinct 
from regular $\beta$-strands, for which the $\mathrm{n}^{\prime}-\pi^{*}$ band $\lambda_{\max }$ is expected at $215 \mathrm{~nm}$. We propose that such dichroic spectrum corresponds to the far-UV CD signature of the $\beta$-roll fold of the calcium-loaded RTX motifs.

Calcium titration experiments revealed that the secondary and tertiary structure changes of the polypeptides occurred at the same calcium concentrations and appeared to be highly cooperative, with $n_{H}$ values around 5 (Fig. $4 \mathrm{~b}$ and Table 2). This indicates that the secondary and tertiary structures are acquired concomitantly and that the overall folding process requires the simultaneous binding of several calcium ions per polypeptide chain. This suggests that the polypeptides may significantly populate only two states: either a calcium-free unfolded state, or a fully folded calcium-bound state in which the RTX motifs bind a calcium ion and adopt a $\beta$-roll structure. Importantly, we have defined a minimal folding domain from the RTX region of CyaA, $\mathrm{RC}_{\mathrm{L}}$ (150 residues), that constitutes a good target for further thermodynamic, kinetic and structural characterizations in order to understand the structure-function relationships of these widespread calcium-binding structures. This polypeptide will be particularly attractive for in-depth biophysical investigations of the transition from a natively unstructured to a folded state.

From a physiological perspective, the present results have a direct implication for the CyaA toxin biogenesis. Prior in vivo studies have suggested a potential coupling between the export of CyaA out of bacteria and its folding into a biologically active conformation ${ }^{21}$. Our present demonstration that the block V subdomain of CyaA only requires the C-terminal extension to acquire a stable 3D structure in the presence of calcium may indeed be particularly relevant for the secretion of the protein through the T1SS machinery ${ }^{26 ; 32}$. Assuming a directional secretion process of the polypeptide from its $\mathrm{C}$-terminus toward the $\mathrm{N}$-terminus, the $\mathrm{C}$ terminal subdomain of CyaA could fold as the polypeptide chain exits the secretion channel 
into the calcium-rich environment of the bacterial extracellular medium. This could facilitate the export and folding of the full-length protein through a molecular ratchet mechanism. 


\section{Material and Methods}

\section{Reagents}

All reagents were of the highest purity grade. Buffer A is $20 \mathrm{mM}$ Hepes, pH 7.4, $100 \mathrm{mM}$ $\mathrm{NaCl}$.

\section{Construction of the RTX polypeptides}

The DNA corresponding to the six studied polypeptides was PCR - amplified using the appropriate primers and the plasmid DNA from pDLE9-RD_CyaA ${ }^{18}$. DNA fragments were PCR amplified with appropriate oligonucleotides, gel purified, digested with BamHI and NdeI restriction enzymes and subcloned into the corresponding sites of the pDLE9-RDSma-Histag plasmid ${ }^{18}$, giving rise to the $\mathrm{pB} 5$ plasmid series. The expression plasmid $\mathrm{pB} 5-\mathrm{NRC}_{\mathrm{L}}$ encodes for the $\mathrm{NRC}_{\mathrm{L}}\left(\mathrm{CyaA}^{1487-1680}\right.$ in native numbering) polypeptide, $\mathrm{pB} 5-\mathrm{RC}_{\mathrm{L}}$ for the $\mathrm{RC}_{\mathrm{L}}$ $\left(\mathrm{CyaA}^{1530-1680}\right)$ polypeptide, $\mathrm{pB} 5-\mathrm{NRC}_{\mathrm{S}}$ for the $\mathrm{NRC}_{\mathrm{S}}\left(\mathrm{CyaA}^{1487-1652}\right)$ polypeptide, $\mathrm{pB} 5-\mathrm{NR}$ for the NR $\left(\mathrm{CyaA}^{1487-1630}\right)$ polypeptide, $\mathrm{pB} 5-\mathrm{RC}_{\mathrm{S}}$ for the $\mathrm{RC}_{\mathrm{S}}\left(\mathrm{CyaA}^{1530-1652}\right)$ polypeptide and pB5-R for R $\left(\mathrm{CyaA}^{1530-1630}\right)$ polypeptide. The polypeptides are presented schematically in Fig. 1 and the corresponding amino-acid sequences are presented in Table S1.

The $C_{S}$ peptide, which corresponds to the short $C$-terminal flanking region $\left(C_{S}\right.$, residues 1631 1652), was synthesized by Genosphere Biotechnologies with an acylated N-terminus and was purified by HPLC. Its purity and molecular mass were checked by mass spectrometry (the purity was higher than 95\%). The long C-terminal flanking region $\left(\mathrm{C}_{\mathrm{L}}\right)$ was obtained by proteolytic cleavage of a variant of the $\mathrm{RC}_{\mathrm{L}}$ polypeptide, $\mathrm{RC}_{\mathrm{LXa}}$, in which Ile1631 was converted into a Gly residue (by site directed mutagenesis of plasmid $\mathrm{pB} 5-\mathrm{RC}_{\mathrm{L}}$ with appropriate oligonucleotides) to create a unique factor Xa cleavage site (LE $\underline{G R}$ ) between the 
$\mathrm{R}$ and $\mathrm{C}_{\mathrm{L}}$ polypeptidic region. Expression and proteolytic cleavage of $\mathrm{RC}_{\mathrm{LXa}}$ are described below.

\section{Polypeptides production and purification}

The RTX polypeptides were over-expressed in the E. coli BLR strain (Novagen, Merck). Briefly, E. coli BLR strain containing the different pB5 plasmids was grown at $30^{\circ} \mathrm{C}$ in 1 liter of LB medium supplemented with $100 \mu \mathrm{g} / \mathrm{ml}$ of ampicilin to an optical density at $600 \mathrm{~nm}$ of 0.8. Expression of the polypeptides was induced by shifting the growth temperature to $42{ }^{\circ} \mathrm{C}$ for 2 hours ${ }^{18}$. Cells were then collected by centrifugation and disrupted by sonication in 20 mM Hepes, $\mathrm{pH}$ 7.4, $100 \mathrm{mM} \mathrm{NaCl}, 10 \mathrm{mM}$ imidazole, $2 \mathrm{mM} \mathrm{CaCl} 2$ supplemented with a protease inhibitor cocktail (Complete, Roche, Mannheim, Germany). After centrifugation (30 min at $13000 \mathrm{rpm}, 4{ }^{\circ} \mathrm{C}$ ), both soluble and insoluble fractions were kept and the inclusion bodies were dissolved in $8 \mathrm{M}$ urea in buffer A. Polypeptides were recovered from both the soluble fraction and the inclusion bodies. RTX polypeptides containing the N-terminal flanking region were mainly found in the inclusion bodies, while the polypeptides lacking the $\mathrm{N}$ region were recovered in the soluble fraction. No differences were detected by fluorescence and $\mathrm{CD}$ spectroscopies for polypeptides purified either from the soluble fraction or the inclusion bodies.

RTX polypeptides purification was performed in four steps. The extracts were loaded on a nickel HiTrap chelating column (GE Healthcare) previously equilibrated in buffer A. The column was washed with $20 \mathrm{mM}$ and $50 \mathrm{mM}$ imidazole and finally polypeptides were eluted in the presence of $500 \mathrm{mM}$ imidazole in $20 \mathrm{mM}$ Hepes, $200 \mathrm{mM} \mathrm{NaCl}$. Polypeptides were further purified by size exclusion chromatography on Sephacryl S200 (20 mM Hepes, pH 7.4, $100 \mathrm{mM} \mathrm{NaCl}$ ) and by ion exchange chromatography on Q sepharose (elution was done with $20 \mathrm{mM}$ Hepes, $500 \mathrm{mM} \mathrm{NaCl} \mathrm{pH}$ 7.4) at room temperature. Ethylenediaminetetraacetic acid (EDTA) at a final concentration of $2 \mathrm{mM}$ was added to samples before desalting on prepacked 
G25SF against $20 \mathrm{mM}$ Hepes, $100 \mathrm{mM} \mathrm{NaCl} \mathrm{pH} 7.4$ (for storage at $-20^{\circ} \mathrm{C}$ ) or against $20 \mathrm{mM}$ $\mathrm{NH}_{4} \mathrm{HCO}_{3}$ and lyophilized. RTX polypeptides batches were analyzed by SDS-PAGE and Nterminal sequencing. Absolute molecular masses were measured by surface enhanced laser desorption/ionization time-of-flight mass spectrometry (SELDI-TOF-MS model PCS 4000, Ciphergen). Polypeptide concentrations were determined with a spectrophotometer using molar extinction coefficients $(280 \mathrm{~nm})$ of $18000 \mathrm{M}^{-1} \mathrm{~cm}^{-1}$ for $\mathrm{NRC}_{\mathrm{L}}$ and $\mathrm{RC}_{\mathrm{L}}, 16500 \mathrm{M}^{-1} \mathrm{~cm}^{-1}$ for $\mathrm{NRC}_{\mathrm{S}}$ and $\mathrm{RC}_{\mathrm{S}}, 9600 \mathrm{M}^{-1} \mathrm{~cm}^{-1}$ for $\mathrm{NR}$ and $9500 \mathrm{M}^{-1} \mathrm{~cm}^{-1}$ for $\mathrm{R}$.

The $\mathrm{RC}_{\mathrm{LXa}}$ polypeptide (with the factor Xa cleavage site) was produced and purify similarly to wild type $\mathrm{RC}_{\mathrm{L}}$. After checking its purity by SDS-PAGE, $\mathrm{RC}_{\mathrm{LXa}}$ was incubated for $24 \mathrm{hrs}$ at 25 ${ }^{\circ} \mathrm{C}$ with 2 units of Factor Xa (GE Healthcare, Saclay, France) per milligram of $\mathrm{RC}_{\mathrm{LXa}}$. The proteolytic cleavage was analyzed by SDS-PAGE and the molecular masses of the resulting polypeptides ( $\mathrm{R}_{\mathrm{Xa}}$ corresponding to the $\mathrm{R}$ protein with 2 additional residues Gly and Arg at the $\mathrm{C}$ terminus, and $\mathrm{C}_{\mathrm{L}}$ which differs from $\mathrm{C}_{\mathrm{L}}$ by the lack of the first 2 residues) were measured by mass spectrometry. The corresponding sequences are shown in Table S1.

\section{Calcium binding assays}

Calcium binding to the RTX polypeptides was measured by a direct binding assay in solution. In this approach, known amounts of calcium (ranging from 0.1 to $3 \mathrm{mM}$ ) were sequentially added to protein solutions and the free calcium concentrations were monitored with calcium electrode. The difference between total added calcium and the measured free calcium corresponds to the protein-bound ions. Calcium potentials were recorded using a $\mathrm{pCa}$ electrode (ELIT 8041, Fisher Scientific). Measurements were done at $25{ }^{\circ} \mathrm{C}$ in $500 \mu 1$ of solution. The electrode was calibrated with buffer $\mathrm{A}$ for $\mathrm{NRC}_{\mathrm{L}}$ and $\mathrm{RC}_{\mathrm{L}}$ or with $20 \mathrm{mM}$ 
Hepes, $20 \mathrm{mM} \mathrm{NaCl}$ for $\mathrm{RC}_{\mathrm{S}}$ and $\mathrm{R}$ in order to decrease the competition effect of $\mathrm{NaCl}$. Polypeptide concentrations ranged from 50 to $200 \mu \mathrm{M}$.

\section{Fluorescence spectroscopy}

Measurements were performed using a FP-6200 spectrofluorimeter (Jasco, Japan) equipped with a Peltier-thermostated cell holder, using $2 \mathrm{ml}$ samples in $1 \mathrm{~cm}$ path-length quartz cells (111-QS from Hellma). A bandwidth of $5 \mathrm{~nm}$ was used for the excitation and emission beams. RTX polypeptides and the $\mathrm{C}_{\mathrm{S}}$ peptide concentrations were $1-2 \mu \mathrm{M}$ for tryptophan intrinsic fluorescence and $2 \mu \mathrm{M}$ for acrylamide quenching and ANS binding experiments. For tryptophan intrinsic fluorescence and acrylamide quenching, the excitation wavelength was fixed at $292 \mathrm{~nm}$. The emission spectra were recorded at $25^{\circ} \mathrm{C}$ and $37{ }^{\circ} \mathrm{C}$, from 300 to $400 \mathrm{~nm}$ at a scan rate of $125 \mathrm{~nm} \cdot \mathrm{min}^{-1}$. Titration experiments of the RTX polypeptides by cations were followed by steady-state tryptophan fluorescence and by tryptophan quenching by acrylamide (for calcium titration only). Maximum emission wavelength $\left(\lambda_{\max }\right)$ and fluorescence intensity ratio $360 \mathrm{~nm}$ over $320 \mathrm{~nm}$ (FIR 360/320) represent the average of three values obtained from emission spectra that were corrected for buffer recordings. To follow the potential apparition of macroscopic aggregates, the Rayleigh band of scattered photons was followed in the fluorimeter (Ex. and Em.: $400 \mathrm{~nm}$ ). Calcium titration followed by ANS fluorescence (5 $\mu \mathrm{M}$; Ex.: $360 \mathrm{~nm}$, Em.: from 460 to $520 \mathrm{~nm}$ ) was monitored at $37{ }^{\circ} \mathrm{C}$. Thermal-induced denaturation of RTX polypeptides in the absence and in the presence of calcium $\left(2 \mathrm{mM} \mathrm{CaCl}_{2}\right.$ for $\mathrm{NRC}_{\mathrm{L}}$ and $\mathrm{RC}_{\mathrm{L}} ; 20 \mathrm{mM} \mathrm{CaCl}$ for $\mathrm{NRC}_{\mathrm{S}}$ and $\mathrm{RC}_{\mathrm{S}}$ ) was followed by ANS fluorescence from 10 to $98{ }^{\circ} \mathrm{C}$ with a temperature increment of $1{ }^{\circ} \mathrm{C}$ between each spectrum at a $9{ }^{\circ} \mathrm{C} /$ hour rate.

\section{Circular dichroism spectroscopy}

CD spectra were recorded on an Aviv circular dichroism spectrometer model 215 equipped 
with a water-cooled Peltier unit. CD experiments were carried out at a scan rate of $0.5 \mathrm{~nm} / \mathrm{sec}$ (step: $0.5 \mathrm{~nm}$; integration time: $1 \mathrm{sec}$ ) with a time constant of $100 \mathrm{msec}$ and a bandwidth of 1 nm. Rectangular quartz Suprasil cells of 1 and $10 \mathrm{~mm}$ path-lengths (110-QS and 114B-QS, Hellma) were used for recording CD activity in far-UV and near-UV regions, respectively. For comparison between the apo-states and holo-states of the different RTX polypeptides, experiments were done at $25{ }^{\circ} \mathrm{C}$ and at $37{ }^{\circ} \mathrm{C}$ in quartz suprasil cells of $0.1 \mathrm{~mm}$ path-lengths (106-QS, Hellma). For calcium titration, the temperature was maintained at $37{ }^{\circ} \mathrm{C}$, and the concentration of calcium was increased by addition of aliquots from stock solutions. For divalent cation titration, temperature was also kept at $37^{\circ} \mathrm{C}$ and the different divalent cations were added from stock solutions to get the human serum concentration and finally to reach a concentration of $2 \mathrm{mM}$. For comparison between secondary (followed in the far-UV) and tertiary (followed by near-UV CD) structural changes induced by calcium or other divalent cations, experiments were done at $37^{\circ} \mathrm{C}$ in rectangular quartz Suprasil cells of 1 and $10 \mathrm{~mm}$ path-lengths (110-QS and 114B-QS, Hellma), respectively. Each far-UV and near-UV CD spectrum represents the average of at least 5 scans. Buffer A $(20 \mathrm{mM}$ Hepes, $100 \mathrm{mM} \mathrm{NaCl}$, $\mathrm{pH}$ 7.4) was used as blank in far-UV and near-UV regions and its spectrum was subtracted to protein $\mathrm{CD}$ spectra. The CD units used were the mean residue ellipticity (MRE), expressed in degrees square centimeter per decimole and per aminoacids $\left(\left(\mathrm{deg}^{*} \mathrm{~cm}^{2}\right) /(\mathrm{dmol} * \mathrm{aa})\right)$, and the molar ellipticity, expressed in degrees square centimeter per decimole $\left(\left(\mathrm{deg}^{*} \mathrm{~cm}^{2}\right) / \mathrm{dmol}\right)$. Secondary structure predictions were done using the SOPMA ${ }^{51}$, PSIpred $^{52 ;}$ 53, Porter $^{54}$, PROF $^{55}$ softwares.

\section{Curve fittings}

Curve fittings are described in Supplementary Material Part I. 


\section{Quasi elastic light scattering}

QELS experiments were realized on a DynaPro MS800 (Wyatt) with the Protein Solution Dynamics software version 6.2.05. The laser power was $100 \%$ and its incident light wavelength was $\lambda_{\text {qels }}: 824.7 \mathrm{~nm}$. The photons count per second was kept below 3000000 . Buffers and samples were filtrated on $0.2 \mu \mathrm{m}$ filters prior to acquisition. A microcuvette of dimensions $3 * 8.5 \mathrm{~mm}(105.251-\mathrm{QS})$ was loaded with $150 \mu \mathrm{L}$ of $55 \mu \mathrm{M}$ polypeptide in buffer A. Samples were allowed to thermal equilibration for 10 minutes in the cell compartment at 25 or $37{ }^{\circ} \mathrm{C}$. Acquisition time was $10 \mathrm{sec}$, with an interval time of $1 \mathrm{sec}$. At least 30 acquisitions were averaged to produce a data collection. A set of three independent data collections was obtained for each experimental condition. The data were processed with SEDFIT 9.2 (analyticalultracentrifugation.com) and analyzed using (i) continuous hydrodynamic radius distribution and (ii) Stokes radii models. The maximum entropy and the Tikhonov-Phillips $2^{\text {nd }}$ derivative regularization procedures were used with a confidence level (F-ratio) of 0.55 . The Stokes-Einstein relation $R_{H}=k_{B} T / 6 \pi \eta D_{t}$ was used to switch between the translational diffusion coefficient, $D_{t}$, and the hydrodynamic radius, $R_{H}$. The solvent viscosity was calculated with the SEDNTERP software (http://www.rasmb.bbri.org).

\section{Size exclusion chromatography followed by intrinsic viscosity and molecular mass measurements}

A Superdex 200 column (GE Healthcare) was used for size exclusion chromatography (SEC). The system was controlled by a GPCmax module and connected on-line to a triple detector array (TDA) model 302 (Viscotek Ltd., Houston, Basingstoke, U.K.). The oven of the TDA contains (i) a static light scattering cell with two photodiode detectors at $7^{\circ}$ for low angle (LALS) and at $90^{\circ}$ for right angle laser light scattering (RALS), (ii) a deflection refractometer, (iii) a photometer and (iv) a differential viscometer. The general procedures are 
described elsewhere ${ }^{41 ; 56}$. All solutions were filtered on $0.2 \mu \mathrm{m}$ filters and allowed to equilibrate at $22{ }^{\circ} \mathrm{C}$ prior to running. The SEC experiments were performed at $22{ }^{\circ} \mathrm{C}$ while the detections in the TDA oven were done at $25{ }^{\circ} \mathrm{C}$. All experimental sequences contained injections of NIST-1923 PolyEthylene Oxide 22-KDa (PEO from Viscotek PolyCal ${ }^{\mathrm{TM}}$ TDSPEO-N at $4 \mathrm{~g} / \mathrm{L}, 100 \mu \mathrm{L}$; intrinsic viscosity: $39 \mathrm{~mL} / \mathrm{g}$ in our experimental conditions) and BSA (SIGMA A0281, $2.4 \mathrm{mg} / \mathrm{mL}, 200 \mu \mathrm{l}$; intrinsic viscosity: $4 \mathrm{~mL} / \mathrm{g}$ ) used for TDA internal constants calibration, followed by the samples of apo- or holo- proteins. BSA and PEO were used for molecular mass and intrinsic viscosity calibration, respectively. The buffer was either 20 mM Hepes, 100 mM NaCl, 2 mM EDTA pH 7.4 (apo) or 20 mM Hepes, 100 mM NaCl, 2 $\mathrm{mM} \mathrm{CaCl}_{2}, \mathrm{pH} 7.4$ (holo). All data were acquired and processed using the Omnisec software (Viscotek Ltd.). Polypeptide concentrations were determined using the photometer and the deflection refractometer.

\section{Analytical ultracentrifugation}

Sedimentation equilibrium and velocity experiments were performed on a ProteomeLab XL-I analytical ultracentrifuge (Beckman-Coulter) in an AN60-Ti rotor at $25{ }^{\circ} \mathrm{C}$. The samples were filtrated on $0.2 \mu \mathrm{m}$ filters before experiments. Detection of the polypeptide concentration as a function of radial position and time was performed by optical density measurements at a wavelength of $276 \mathrm{~nm}$. For sedimentation equilibrium experiments, samples $(120 \mu \mathrm{L}, 20 \mu \mathrm{M})$ were loaded in a $1.2 \mathrm{~mm}$-thick two channels epon centerpiece. Samples were centrifuged for 31 hours at a rotor speed of $18000 \mathrm{rpm}, 25 \mathrm{hrs}$ at $24000 \mathrm{rpm}, 19 \mathrm{hrs}$ at $30000 \mathrm{rpm}$ and finally for $13 \mathrm{hrs}$ at $36000 \mathrm{rpm}$. Data were recorded for each speed after controlling that sedimentation/diffusion equilibrium had been effectively reached. Baseline was measured at $60000 \mathrm{rpm}$ after 5 hrs. Radial distributions were analyzed by global fitting of the four speeds using the one species model in the Ultrascan 9.5 software ${ }^{57}$. The partial specific volume 
deduced from equilibrium experiments, $\bar{v}_{e q}$, was obtained by fixing the molecular mass to the mass of the monomer determined by mass spectrometry.

For sedimentation velocity experiments, the polypeptide samples $(400 \mu \mathrm{L}, 20 \mu \mathrm{M})$ were loaded in a $1.2 \mathrm{~mm}$-thick two channels aluminium centerpiece and spun at $60000 \mathrm{rpm}$. Data were analyzed with the Sedfit 11.3 software ${ }^{58}$ using a continuous size distribution c(s) model to extract the sedimentation coefficient, S.

\section{Protein shape and hydration}

For the determination of protein shape and hydration, we used a previously described procedure ${ }^{41 ; 56}$. Briefly, the molecular mass $(\mathrm{M})$, the intrinsic viscosity $[\eta]$, the hydrodynamic radius $\mathrm{R}_{\mathrm{H}}$ and the partial specific volume $\bar{v}$ of the protein are required (see below for details). From the Svedberg equation $S=M(1-\rho \bar{v}) /\left(N_{A} f\right)$ and the relations $f D_{t}=k_{B} T$ and $N_{A} k_{B}=R$, the sedimentation coefficient $\mathrm{S}$ is expressed $S=\left[D_{t} M(1-\rho \bar{v})\right] / R T$. We then exchange the translational diffusion coefficient $D_{t}$ to the $R_{H}$ expression using the Stokes Einstein relation $D_{t}=k_{B} T /\left(6 \pi \eta R_{H}\right)$, given $S=M(1-\rho \bar{v}) /\left(6 \pi \eta N_{A} R_{H}\right)$. We inverted this relation to express the partial specific volume as a function of the experimental data measured by AUC (S), DLS $\left(\mathrm{R}_{\mathrm{H}}\right)$, SEC-TDA and SELDI (M) as follows $\bar{v}=\left(1-\left(6 \pi \eta N_{A} R_{H} S / M\right)\right) / \rho$. This provided us with the first set of hydrodynamic parameters $\left\{M ;[\eta] ; R_{H}{ }^{D L S} ; \bar{v}\right\}_{1}$.

We also used the partial specific volume determined by equilibrium AUC, $\bar{v}_{e q}$, to estimate the $\mathrm{R}_{\mathrm{H}}$ value using the Svedberg equation. We input the values of $\mathrm{S}, \mathrm{M}$ and $\bar{v}_{e q}$ to calculate the $R_{H}$ according to $R_{H}=M\left(1-\rho \bar{v}_{e q}\right) /\left(6 \pi \eta N_{A} S\right)$. This provides us the second set of hydrodynamic parameters $\left\{M ;[\eta] ; \bar{v}_{e q} ; R_{H}\right\}_{2}$. The solvent viscosity and density were calculated with SEDNTERP. 
The intrinsic viscosity of a protein, $[\eta]$ (see ${ }^{47}$ for a review), is expressed according to the relation $[\eta]=v V_{s}=v(\bar{v}+\delta / \rho)$. The intrinsic viscosity is the product of (i) a hydrodynamic function, the viscosity increment $v^{59}$, and (ii) the swollen volume $V_{S}$. The viscosity increment is related to the shape of the molecule. A $v$ value of 2.5 suggests that the protein adopts a spherical shape, while increasing values of $v$ are indicative of ellipsoid shapes. The swollen volume is the sum of volumic factors, i.e., the partial specific volume, $\bar{v}$, and the time-averaged apparent hydration $(\delta)$ of the protein. The hydration parameter includes the water molecules bound to the protein and the water molecules entrained by the diffusion of the protein.

Here, we used three approaches to calculate protein shape and hydration. First, the shape factor $v$ was calculated from the experimental values of $\mathrm{M},[\eta]$, and $\mathrm{R}_{\mathrm{H}}$ using the Einstein viscosity relation $M[\eta]=v V_{H} N_{A}$ inverted to $v=M[\eta] / V_{H} N_{A}$, where $V_{H}$ is the hydrodynamic volume defined by $V_{H}=4 \pi R_{H}^{3} / 3$. The viscosity increment was then used to estimate the ratio $(\mathrm{a} / \mathrm{b}=\vartheta)$ of the semi-axes $\mathrm{a}$ and $\mathrm{b}($ with $\mathrm{a}>\mathrm{b})$ for an equivalent prolate or oblate ellipsoid ${ }^{60}$. The solution for a prolate ellipsoid $\left(R_{H}^{3}=a^{*} b^{*} b\right)$ is given by $a=R_{H} * \vartheta^{1 / 3}$ and $b=a / \vartheta$ while the solution for an oblate ellipsoid $\left(R_{H}^{3}=a^{*} a * b\right)$ is given by $b=R_{H} * \vartheta^{-1 / 3}$ and $a=\vartheta * b$. Then, from the intrinsic viscosity relation $[\eta]=v(\bar{v}+\delta / \rho)$, the hydration $\delta$ is calculated from the parameters $[\eta], v$ and $\bar{v}$ according to $\delta=(([\eta] / v)-\bar{v}) o$

The second way to calculate protein shape and hydration was to determine the hydration $(\delta)$ from the experimental values of $\mathrm{M}, \bar{v}$ and $R_{H}$ using the relation $M(\bar{v}+\delta)=V_{H} N_{A}$. Then, the viscosity increment $v$ is calculated with the intrinsic viscosity relation $v=[\eta] /(\bar{v}+\delta / \rho)$. 
Finally, we calculated the Perrin hydrodynamic function $\mathrm{P}^{61}$ as an alternative estimation of the semi-axial ratio $(\mathrm{a} / \mathrm{b}=\vartheta)$, according to $P=\left(f / f_{0}\right) /\left[((\delta / \bar{v} \rho)+1)^{1 / 3}\right]^{62}$. For this purpose, we combined the frictional ratio $f / f_{0}$ and the previously determined hydration values $\delta . R_{H}$ values (derived from $\mathrm{S}$ and $D_{t}$ ) were used to calculate the frictional ratio $f / f_{0}$ from the relation $f / f_{0}=R_{H} / R_{0}$. The anhydrous radius $R_{0}$ (by definition with $\delta=0$ ), is defined by $M \bar{v}=V_{0} N_{A}=\frac{4 \pi R_{0}^{3}}{3} N_{A}$, which gives $R_{0}=\left(\frac{3 M \bar{v}}{4 \pi N_{A}}\right)^{1 / 3}$. 


\section{References}

1. Weiss, A. A. \& Hewlett, E. L. (1986). Virulence factors of Bordetella pertussis. Annu Rev Microbiol 40, 661-86.

2. Ladant, D. \& Ullmann, A. (1999). Bordetella pertussis adenylate cyclase: a toxin with multiple talents. Trends Microbiol 7, 172-6.

3. Vojtova, J., Kamanova, J. \& Sebo, P. (2006). Bordetella adenylate cyclase toxin: a swift saboteur of host defense. Curr Opin Microbiol 9, 69-75.

4. Glaser, P., Sakamoto, H., Bellalou, J., Ullmann, A. \& Danchin, A. (1988). Secretion of cyclolysin, the calmodulin-sensitive adenylate cyclase-haemolysin bifunctional protein of Bordetella pertussis. Embo J 7, 3997-4004.

5. Rogel, A., Schultz, J. E., Brownlie, R. M., Coote, J. G., Parton, R. \& Hanski, E. (1989). Bordetella pertussis adenylate cyclase: purification and characterization of the toxic form of the enzyme. Embo $J \mathbf{8}, 2755-60$.

6. Bellalou, J., Ladant, D. \& Sakamoto, H. (1990). Synthesis and secretion of Bordetella pertussis adenylate cyclase as a 200-kilodalton protein. Infect Immun 58, 1195-200.

7. Confer, D. L. \& Eaton, J. W. (1982). Phagocyte impotence caused by an invasive bacterial adenylate cyclase. Science 217, 948-50.

8. Hanski, E. \& Farfel, Z. (1985). Bordetella pertussis invasive adenylate cyclase. Partial resolution and properties of its cellular penetration. J Biol Chem 260, 5526-32.

9. El-Azami-El-Idrissi, M., Bauche, C., Loucka, J., Osicka, R., Sebo, P., Ladant, D. \& Leclerc, C. (2003). Interaction of Bordetella pertussis adenylate cyclase with CD11b/CD18: Role of toxin acylation and identification of the main integrin interaction domain. J Biol Chem 278, 38514-21.

10. Guermonprez, P., Khelef, N., Blouin, E., Rieu, P., Ricciardi-Castagnoli, P., Guiso, N., Ladant, D. \& Leclerc, C. (2001). The adenylate cyclase toxin of Bordetella pertussis binds to target cells via the alpha(M)beta(2) integrin (CD11b/CD18). $J$ Exp Med 193, 1035-44.

11. Rogel, A. \& Hanski, E. (1992). Distinct steps in the penetration of adenylate cyclase toxin of Bordetella pertussis into sheep erythrocytes. Translocation of the toxin across the membrane. J Biol Chem 267, 22599-605.

12. Hewlett, E. L., Gordon, V. M., McCaffery, J. D., Sutherland, W. M. \& Gray, M. C. (1989). Adenylate cyclase toxin from Bordetella pertussis. Identification and purification of the holotoxin molecule. J Biol Chem 264, 19379-84.

13. Karst, J., Sotomayor Pérez, A., Guijarro, J., Raynal, B., Chenal, A. \& Ladant, D. (in press). Calmodulin-Induced Conformational and Hydrodynamic Changes of the Catalytic Domain of Bordetella pertussis Adenylate Cyclase Toxin. Biochemistry.

14. Mock, M. \& Ullmann, A. (1993). Calmodulin-activated bacterial adenylate cyclases as virulence factors. Trends Microbiol 1, 187-92.

15. Khelef, N., Zychlinsky, A. \& Guiso, N. (1993). Bordetella pertussis induces apoptosis in macrophages: role of adenylate cyclase-hemolysin. Infect Immun 61, 4064-71.

16. Coote, J. G. (1992). Structural and functional relationships among the RTX toxin determinants of gram-negative bacteria. FEMS Microbiol Rev 8, 137-61.

17. Welch, R. A. (1991). Pore-forming cytolysins of gram-negative bacteria. Mol Microbiol 5, 521-8.

18. Bauche, C., Chenal, A., Knapp, O., Bodenreider, C., Benz, R., Chaffotte, A. \& Ladant, D. (2006). Structural and functional characterization of an essential RTX subdomain of Bordetella pertussis adenylate cyclase toxin. J Biol Chem 281, 16914-26. 
19. Bejerano, M., Nisan, I., Ludwig, A., Goebel, W. \& Hanski, E. (1999). Characterization of the C-terminal domain essential for toxic activity of adenylate cyclase toxin. Mol Microbiol 31, 381-92.

20. Fiser, R. \& Konopasek, I. (2009). Different modes of membrane permeabilization by two RTX toxins: HlyA from Escherichia coli and CyaA from Bordetella pertussis. Biochim Biophys Acta 1788, 1249-54.

21. Gray, M. C., Donato, G. M., Jones, F. R., Kim, T. \& Hewlett, E. L. (2004). Newly secreted adenylate cyclase toxin is responsible for intoxication of target cells by Bordetella pertussis. Mol Microbiol 53, 1709-19.

22. Iwaki, M., Ullmann, A. \& Sebo, P. (1995). Identification by in vitro complementation of regions required for cell-invasive activity of Bordetella pertussis adenylate cyclase toxin. Mol Microbiol 17, 1015-24.

23. Morova, J., Osicka, R., Masin, J. \& Sebo, P. (2008). RTX cytotoxins recognize beta2 integrin receptors through N-linked oligosaccharides. Proc Natl Acad Sci U S A 105, 5355-60.

24. Welch, R. A. (2001). RTX toxin structure and function: a story of numerous anomalies and few analogies in toxin biology. Curr Top Microbiol Immunol 257, 85-111.

25. Boehm, D. F., Welch, R. A. \& Snyder, I. S. (1990). Domains of Escherichia coli hemolysin (HlyA) involved in binding of calcium and erythrocyte membranes. Infect Immun 58, 1959-64.

26. Delepelaire, P. (2004). Type I secretion in gram-negative bacteria. Biochim Biophys Acta 1694, 149-61.

27. Ludwig, A., Jarchau, T., Benz, R. \& Goebel, W. (1988). The repeat domain of Escherichia coli haemolysin (HlyA) is responsible for its Ca2+-dependent binding to erythrocytes. Mol Gen Genet 214, 553-61.

28. Rose, T., Sebo, P., Bellalou, J. \& Ladant, D. (1995). Interaction of calcium with Bordetella pertussis adenylate cyclase toxin. Characterization of multiple calciumbinding sites and calcium-induced conformational changes. J Biol Chem 270, 26370-6.

29. Sanchez-Magraner, L., Viguera, A. R., Garcia-Pacios, M., Garcillan, M. P., Arrondo, J. L., de la Cruz, F., Goni, F. M. \& Ostolaza, H. (2007). The calcium-binding Cterminal domain of Escherichia coli alpha-hemolysin is a major determinant in the surface-active properties of the protein. $J$ Biol Chem 282, 11827-35.

30. Boehm, D. F., Welch, R. A. \& Snyder, I. S. (1990). Calcium is required for binding of Escherichia coli hemolysin (HlyA) to erythrocyte membranes. Infect Immun 58, 19518.

31. Ostolaza, H., Soloaga, A. \& Goni, F. M. (1995). The binding of divalent cations to Escherichia coli alpha-haemolysin. Eur J Biochem 228, 39-44.

32. Holland, I. B., Schmitt, L. \& Young, J. (2005). Type 1 protein secretion in bacteria, the ABC-transporter dependent pathway (review). Mol Membr Biol 22, 29-39.

33. Baumann, U., Wu, S., Flaherty, K. M. \& McKay, D. B. (1993). Three-dimensional structure of the alkaline protease of Pseudomonas aeruginosa: a two-domain protein with a calcium binding parallel beta roll motif. Embo J 12, 3357-64.

34. Lilie, H., Haehnel, W., Rudolph, R. \& Baumann, U. (2000). Folding of a synthetic parallel beta-roll protein. FEBS Lett 470, 173-7.

35. Meier, R., Drepper, T., Svensson, V., Jaeger, K. E. \& Baumann, U. (2007). A calciumgated lid and a large beta-roll sandwich are revealed by the crystal structure of extracellular lipase from Serratia marcescens. J Biol Chem 282, 31477-83.

36. Dunker, A. K., Lawson, J. D., Brown, C. J., Williams, R. M., Romero, P., Oh, J. S., Oldfield, C. J., Campen, A. M., Ratliff, C. M., Hipps, K. W., Ausio, J., Nissen, M. S., Reeves, R., Kang, C., Kissinger, C. R., Bailey, R. W., Griswold, M. D., Chiu, W., 
Garner, E. C. \& Obradovic, Z. (2001). Intrinsically disordered protein. J Mol Graph Model 19, 26-59.

37. Dyson, H. J. \& Wright, P. E. (2005). Intrinsically unstructured proteins and their functions. Nat Rev Mol Cell Biol 6, 197-208.

38. Eliezer, D. (2009). Biophysical characterization of intrinsically disordered proteins. Curr Opin Struct Biol 19, 23-30.

39. Fink, A. L. (2005). Natively unfolded proteins. Curr Opin Struct Biol 15, 35-41.

40. Wright, P. E. \& Dyson, H. J. (2009). Linking folding and binding. Curr Opin Struct Biol 19, 31-8.

41. Chenal, A., Guijarro, J. I., Raynal, B., Delepierre, M. \& Ladant, D. (2009). RTX calcium binding motifs are intrinsically disordered in the absence of calcium: implication for protein secretion. J Biol Chem 284, 1781-9.

42. Glaser, P., Danchin, A., Ladant, D., Barzu, O. \& Ullmann, A. (1988). Bordetella pertussis adenylate cyclase: the gene and the protein. Tokai J Exp Clin Med 13 Suppl, 239-52.

43. Sebo, P. \& Ladant, D. (1993). Repeat sequences in the Bordetella pertussis adenylate cyclase toxin can be recognized as alternative carboxy-proximal secretion signals by the Escherichia coli alpha-haemolysin translocator. Mol Microbiol 9, 999-1009.

44. Platt, J. R. (1949). Classification of Spectra of Cata-Condensed Hydrocarbons. J. Chem. Phys. 17, 484-495.

45. Fasman, G. D. (1996). Circular Dichroism and the Conformational Analysis of Biomolecules. Plenum Press, New York and London.

46. Eftink, M. R. \& Ghiron, C. A. (1981). Fluorescence quenching studies with proteins. Anal Biochem 114, 199-227.

47. Harding, S. E. (1997). The intrinsic viscosity of biological macromolecules. Progress in measurement, interpretation and application to structure in dilute solution. Prog Biophys Mol Biol 68, 207-62.

48. Uversky, V. N. (1993). Use of fast protein size-exclusion liquid chromatography to study the unfolding of proteins which denature through the molten globule. Biochemistry 32, 13288-98.

49. Wilkins, D. K., Grimshaw, S. B., Receveur, V., Dobson, C. M., Jones, J. A. \& Smith, L. J. (1999). Hydrodynamic radii of native and denatured proteins measured by pulse field gradient NMR techniques. Biochemistry 38, 16424-31.

50. Uversky, V. N. (2002). What does it mean to be natively unfolded? Eur J Biochem 269, 2-12.

51. Geourjon, C. \& Deleage, G. (1995). SOPMA: significant improvements in protein secondary structure prediction by consensus prediction from multiple alignments. Comput Appl Biosci 11, 681-4.

52. McGuffin, L. J., Bryson, K. \& Jones, D. T. (2000). The PSIPRED protein structure prediction server. Bioinformatics 16, 404-5.

53. Jones, D. T. (1999). Protein secondary structure prediction based on position-specific scoring matrices. Journal of molecular biology 292, 195-202.

54. Pollastri, G. \& McLysaght, A. (2005). Porter: a new, accurate server for protein secondary structure prediction. Bioinformatics 21, 1719-20.

55. Ouali, M. \& King, R. D. (2000). Cascaded multiple classifiers for secondary structure prediction. Protein Sci 9, 1162-76.

56. Bourdeau, R. W., Malito, E., Chenal, A., Bishop, B. L., Musch, M. W., Villereal, M. L., Chang, E. B., Mosser, E. M., Rest, R. F. \& Tang, W. J. (2009). Cellular functions and X-ray structure of anthrolysin $\mathrm{O}$, a cholesterol-dependent cytolysin secreted by Bacillus anthracis. J Biol Chem 284, 14645-56. 
57. Cao, W. \& Demeler, B. (2005). Modeling analytical ultracentrifugation experiments with an adaptive space-time finite element solution of the Lamm equation. Biophys $J$ 89, 1589-602.

58. Schuck, P. (2000). Size-distribution analysis of macromolecules by sedimentation velocity ultracentrifugation and lamm equation modeling. Biophys $J$ 78, 1606-19.

59. Simha, R. (1940). The influence of Brownian movement on the viscosity of solutions. J. Phys. Chem. 44, 25-34.

60. Harding, S. E. \& Colfen, H. (1995). Inversion formulae for ellipsoid of revolution macromolecular shape functions. Anal Biochem 228, 131-42.

61. Perrin, F. (1936). Mouvement brownien d'un ellipsoïde (II). Rotation libre et dépolarisation des fluorescences. Translation et diffusion de molécules ellipsoïdales. $J$. Phys. Rad. 7, 1-11.

62. Squire, P. G. \& Himmel, M. E. (1979). Hydrodynamics and protein hydration. Arch. Biochem. Biophys. 196, 165-177. 


\section{Figure legends}

Fig. 1. Schematic representation of the RTX polypeptides. The primary sequence of block V of CyaA (residues 1487 to 1680 ) was separated into 4 distinct regions: the N-terminal flanking region $(\mathrm{N})$ from residues 1487 to 1529; the RTX motifs regions (R; each of the 9 RTX motif is represented by a black box) from residues 1530 to 1630 ; the proximal Cterminal flanking region (the short $\mathrm{C}$ region, $\mathrm{C}_{\mathrm{S}}$ ) from residues 1631 to 1652 and the long $\mathrm{C}$ terminal flanking region from residues 1631 to $1680\left(\mathrm{C}_{\mathrm{L}}\right)$. The location of the two tryptophan residues at position 1621 and 1645 is also indicated.

Fig. 2. Ratio of fluorescence intensities at 360 and $320 \mathrm{~nm}\left(\mathrm{FIR}_{360 / 320}\right)$ of RTX polypeptides as a function of calcium concentration. $-\mathrm{NRC}_{\mathrm{L}} ; \mathrm{O}, \mathrm{RC}_{\mathrm{L}} ; \boldsymbol{\Delta}, \mathrm{NRC}_{\mathrm{S}} ; \triangle, \mathrm{RC}_{\mathrm{S}}, \boldsymbol{\mathbf { }}, \mathrm{NR}$ and $\square$, R. Polypeptide concentration were $1 \mu \mathrm{M}$ for $\mathrm{NRC}_{\mathrm{L}}, \mathrm{RC}_{\mathrm{L}}, \mathrm{NRC}_{\mathrm{S}}$ and $\mathrm{RC}_{\mathrm{S}}$ and $2 \mu \mathrm{M}$ for NR and R. Experimental conditions: buffer A, $37{ }^{\circ} \mathrm{C}$.

Fig. 3. Far-UV CD spectra of $\mathrm{NRC}_{\mathrm{L}}(\mathrm{a}), \mathrm{RC}_{\mathrm{L}}$ (b), $R C_{\mathrm{S}}$ (c) and $\mathrm{R}$ (d) polypeptides in the absence (dotted line) or in the presence of calcium $\left(2 \mathrm{mM}\right.$ for $\mathrm{NRC}_{\mathrm{L}}$ and $\mathrm{RC}_{\mathrm{L}}$ and $20 \mathrm{mM}$ for $\mathrm{RC}_{\mathrm{S}}$ and $\mathrm{R}$; continuous line). Polypeptide concentration ranged from 20 to $30 \mu \mathrm{M}$. Experimental conditions: buffer A, $37^{\circ} \mathrm{C}$.

Fig. 4. Calcium-induced conformational changes followed by circular dichroism in the farUV region. (a), Far-UV $\mathrm{CD}$ spectra of $\mathrm{RC}_{\mathrm{L}}(4 \mu \mathrm{M}$ polypeptide $)$ at various calcium concentrations ranging from 0 (top curve) to $10 \mathrm{mM}$ (bottom curve). (b), Mean residual ellipticity followed at $218 \mathrm{~nm}$ as a function of calcium concentration for $\bullet, \mathrm{NRC}_{\mathrm{L}} ; \mathrm{O}, \mathrm{RC}_{\mathrm{L}}$; $\triangle, \mathrm{RC}_{\mathrm{S}}$ and $\square, \mathrm{R}$ in buffer $\mathrm{A}$ and $\diamond, \mathrm{RC}_{\mathrm{S}}$ in $20 \mathrm{mM}$ Hepes, $20 \mathrm{mM} \mathrm{NaCl}$. Polypeptide concentration was $4 \mu \mathrm{M}$. (c) Difference of holo-state minus apo-state spectra for $\mathrm{NRC}_{\mathrm{L}}(21$ 
$\mu \mathrm{M}$; thin line), $\mathrm{RC}_{\mathrm{L}}\left(34 \mu \mathrm{M}\right.$; thick line) and $\mathrm{RC}_{\mathrm{S}}(29 \mu \mathrm{M}$; dotted line $)$ polypeptides. Experimental conditions: buffer A, $37^{\circ} \mathrm{C}$.

Fig. 5. Far-UV CD spectra in molecular ellipticity units (see Material and methods for details). (a), Spectra showing the holo-state minus the apo-state for $\mathrm{NRC}_{\mathrm{L}}$ (thin line) and $\mathrm{RC}_{\mathrm{L}}$ (thick line) polypeptides. (b), Spectra showing the difference between $\mathrm{NRC}_{\mathrm{L}}$ and $\mathrm{RC}_{\mathrm{L}}$ in the apo-state (dashed line) and in the holo-state (continuous line). (c), Spectra showing the difference between apo $\mathrm{RC}_{\mathrm{L}}$ and apo $\mathrm{RC}_{\mathrm{S}}$ (dashed line) and the difference between holo $\mathrm{RC}_{\mathrm{L}}$ and holo $\mathrm{RC}_{\mathrm{S}}$ (continuous line). Polypeptide concentration was $21 \mu \mathrm{M}$ for $\mathrm{NRC}_{\mathrm{L}}, 31 \mu \mathrm{M}$ for $\mathrm{RC}_{\mathrm{L}}$ and $55 \mu \mathrm{M}$ for $\mathrm{RC}_{\mathrm{S}}$. Experimental conditions: buffer $\mathrm{A}, 37^{\circ} \mathrm{C}$.

Fig. 6. Near-UV CD spectra of $R(a) R C_{L}$ (b) and $N R C_{L}$ (c) in the absence (dotted line) or in the presence of $2 \mathrm{mM}$ calcium (continuous line). Polypeptide concentrations were $33 \mu \mathrm{M}$ for $\mathrm{R}, 68 \mu \mathrm{M}$ for $\mathrm{RC}_{\mathrm{L}}$ and $20 \mu \mathrm{M}$ for $\mathrm{NRC}_{\mathrm{L}}$. (d), Ellipticity changes followed at $297 \mathrm{~nm}(\boldsymbol{\bullet}$, left axis) and at $218 \mathrm{~nm}\left(\mathrm{O}\right.$, right axis) for $\mathrm{RC}_{\mathrm{L}}(30 \mu \mathrm{M})$ as a function of calcium concentration. Near-UV CD units are in molecular ellipticity and far-UV CD units are in mean residual ellipticity (see Material and methods for details). Experimental conditions: buffer A, $37^{\circ} \mathrm{C}$.

Fig. 7. Collisional acrylamide quenching of tryptophan fluorescence. Modified-Stern-Volmer plot of tryptophan quenching by acrylamide of apo- $\mathrm{RC}_{\mathrm{L}}(\square)$, holo- $\mathrm{RC}_{\mathrm{L}}(\boldsymbol{\bullet})$, apo-R $(\times)$ and L-Trp (O). Polypeptide concentration was $2 \mu \mathrm{M}$ in buffer A, $37^{\circ} \mathrm{C}$.

Fig. 8. Hydrodynamic properties of RTX polypeptides monitored by SEC-TDA. Upper panels: Polypeptides were analyzed by size exclusion chromatography on a Superdex 200 connected to a Triple Detector Array as described under "Material and Methods". Right angle 
Table 1. Parameters of calcium-induced conformational changes followed by tryptophan intrinsic fluorescence.

\begin{tabular}{cccccccc} 
Buffer & & $\mathbf{N R C}_{\mathbf{L}}$ & $\mathbf{R C}_{\mathbf{L}}$ & $\mathbf{N R C}_{\mathbf{S}}$ & $\mathbf{N R}$ & $\mathbf{R C}_{\mathbf{S}}$ & $\mathbf{R}$ \\
\hline & $\lambda_{\max }{ }^{1}$ & 353 & 353 & 354 & 356 & 355 & 357 \\
& $\lambda_{\max }{ }^{2}$ & 346 & 346 & 348 & 356 & 349 & 357 \\
\cline { 2 - 7 } $20 \mathrm{mM} \mathrm{Hepes}$ \\
$100 \mathrm{mM} \mathrm{NaCl}$ & $\mathbf{K}_{\mathbf{D}}{ }^{3}$ & $0.45 \pm 0.02$ & $0.55 \pm 0.01$ & $3.0 \pm 0.5$ & $\mathrm{~N} / \mathrm{A}$ & $5.3 \pm 0.1$ & $\mathrm{~N} / \mathrm{A}$ \\
& $\mathbf{n}_{\mathbf{H}}{ }^{3}$ & $6 \pm 1$ & $6 \pm 1$ & $3 \pm 1$ & $\mathrm{~N} / \mathrm{A}$ & $4 \pm 1$ & $\mathrm{~N} / \mathrm{A}$ \\
\hline $\begin{array}{c}20 \mathrm{mM} \mathrm{Hepes} \\
20 \mathrm{mM} \mathrm{NaCl}\end{array}$ & $\mathbf{K}_{\mathbf{D}}{ }^{3}$ & $0.12 \pm 0.01$ & $0.15 \pm 0.01$ & $0.6 \pm 0.1$ & $\mathrm{~N} / \mathrm{A}$ & $1.5 \pm 0.2$ & $\mathrm{~N} / \mathrm{A}$ \\
\hline
\end{tabular}

${ }^{1}$ In the absence of calcium

${ }^{2}$ In the presence of $2 \mathrm{mM} \mathrm{CaCl}_{2}$ for $\mathrm{NRC}_{\mathrm{L}}$ and $\mathrm{RC}_{\mathrm{L}}$ and $20 \mathrm{mM} \mathrm{CaCl}_{2}$ for $\mathrm{NRC}_{\mathrm{S}}, \mathrm{NR}, \mathrm{RC}_{\mathrm{S}}$ and $\mathrm{R}$.

${ }^{3}$ Determined from experimental curves of ratio of $\mathrm{FI}_{360} / \mathrm{FI}_{320}$ as a function of calcium concentration.

$\mathrm{K}_{\mathrm{D}}$ : Equilibrium dissociation constant, $\mathrm{mM}$

$\mathrm{n}_{\mathrm{H}}$ : Hill number

N/A : not applicable 
Table 2. Parameters of calcium-induced conformational changes followed by far-UV circular dichroism.

\begin{tabular}{|c|c|c|c|c|c|}
\hline Buffer & & $\mathrm{NRC}_{\mathbf{L}}$ & $\mathbf{R C}_{\mathbf{L}}$ & $\mathrm{NRC}_{\mathbf{S}}$ & $\mathbf{R C}_{\mathrm{S}}$ \\
\hline \multirow{2}{*}{$\begin{array}{l}20 \mathrm{mM} \text { Hepes } \\
100 \mathrm{mM} \mathrm{NaCl}\end{array}$} & $\mathrm{K}_{\mathrm{D}}, \mathrm{mM}$ & $0.7 \pm 0.04$ & $0.6 \pm 0.01$ & $\mathrm{~N} / \mathrm{A}$ & N/A \\
\hline & $\mathrm{n}_{\mathrm{H}}$ & $5 \pm 1$ & $5 \pm 1$ & N/A & N/A \\
\hline \multirow{2}{*}{$\begin{array}{l}20 \mathrm{mM} \text { Hepes } \\
20 \mathrm{mM} \mathrm{NaCl}\end{array}$} & $\mathrm{K}_{\mathrm{D}}, \mathrm{mM}$ & $0.25 \pm 0.02$ & $0.26 \pm 0.04$ & N/A & $1.5 \pm 0.4$ \\
\hline & $\mathrm{n}_{\mathrm{H}}$ & $4 \pm 1$ & $5 \pm 1$ & N/A & $3 \pm 1$ \\
\hline
\end{tabular}

$\mathrm{n}_{\mathrm{H}}$ : Hill number

N/A : not applicable 
Table 3. Parameters of tryptophan fluorescence quenching by acrylamide.

\begin{tabular}{|c|c|c|c|c|c|c|c|}
\hline & Parameters & $\mathrm{NRC}_{\mathrm{L}}$ & $\mathbf{R C}_{\mathbf{L}}$ & $\mathrm{NRC}_{S}$ & NR & $\mathbf{R C}_{\mathbf{S}}$ & $\mathbf{R}$ \\
\hline \multirow{3}{*}{ Apo-state } & $\mathrm{Ksv}^{\mathrm{a}}$ & 17.1 & 14.2 & 18.9 & 16.9 & 15.7 & 17.1 \\
\hline & $\mathrm{Ka}^{\mathrm{b}}$ & 15.6 & 12.9 & 15.2 & 15.5 & 14.1 & 15.9 \\
\hline & $\mathrm{fa}^{\mathrm{c}}$ & 1.05 & 1.07 & 1.05 & 1.01 & 1.06 & 1.04 \\
\hline \multirow{3}{*}{ Holo-state } & $\mathrm{Ksv}^{\mathrm{a}}$ & 8.5 & 7.85 & 7.3 & N/A & 12.9 & N/A \\
\hline & $\mathrm{Ka}^{\mathrm{b}}$ & 8.9 & 6.9 & 8.2 & N/A & 10.1 & N/A \\
\hline & $\mathrm{fa}^{\mathrm{c}}$ & 0.99 & 0.99 & 1.00 & N/A & 1.06 & N/A \\
\hline
\end{tabular}

${ }^{a}$ Stern-Volmer constant $\left(\mathrm{M}^{-1}\right)$

${ }^{\mathrm{b}}$ Stern-Volmer constant of the fraction of fluorescence accessible to the quencher $\left(\mathrm{M}^{-1}\right)$

${ }^{\mathrm{c}}$ fraction of fluorescence accessible to the quencher.

N/A : not applicable 
Table 4. Hydrodynamic parameters of $\mathrm{RC}_{\mathrm{L}}$ and $\mathrm{R}$ polypeptides in the absence or in presence of calcium.

\begin{tabular}{|c|c|c|c|c|}
\hline Parameters & $\mathbf{R C}_{\mathbf{L}}$ & $\mathrm{RC}_{\mathrm{L}}+$ Calcium & $\mathbf{R}$ & $\mathbf{R}+$ Calcium \\
\hline $\begin{array}{l}\text { Intrinsic viscosity } \\
(\mathrm{mL} / \mathrm{g})\end{array}$ & $13.7 \pm 0.2$ & $3.9 \pm 0.1$ & $12.0 \pm 0.3$ & $12.0 \pm 0.3$ \\
\hline $\begin{array}{l}\text { Molecular mass }{ }^{\mathrm{a}} \\
(\mathrm{kDa})\end{array}$ & $17.9 \pm 0.2$ & $18.2 \pm 0.2$ & $12.0 \pm 0.4$ & $11.6 \pm 0.5$ \\
\hline $\mathrm{R}_{\mathrm{H}}^{\mathrm{b}}(\mathrm{nm})$ & $3.2 \pm 0.1$ & $2.2 \pm 0.2$ & $2.7 \pm 0.1$ & $2.7 \pm 0.1$ \\
\hline $\begin{array}{l}\text { Sedimentation } \\
\text { coefficient }^{\mathrm{c}}(\mathrm{S})\end{array}$ & $1.54 \pm 0.1$ & $2.27 \pm 0.2$ & $1.20 \pm 0.1$ & $1.22 \pm 0.1$ \\
\hline $\mathrm{D}_{\mathrm{t}}^{\mathrm{c}}\left(\mathrm{x} 10^{-7}\right)$ & $7.4 \pm 0.07$ & $10.8 \pm 0.10$ & $8.8 \pm 0.05$ & $8.8 \pm 0.04$ \\
\hline Frictional ratio $^{c}(\mathrm{f} / \mathrm{fo})$ & $1.93 \pm 0.03$ & $1.32 \pm 0.02$ & $1.84 \pm 0.01$ & $1.84 \pm 0.01$ \\
\hline $\mathrm{R}_{0}$ anhydrous (nm) & 1.68 & 1.68 & 1.47 & 1.47 \\
\hline $\begin{array}{l}\text { Partial specific } \\
\text { volume }^{\mathrm{d}}(\mathrm{mL} / \mathrm{g})\end{array}$ & $0.699 \pm 0.007$ & $0.696 \pm 0.003$ & $0.699 \pm 0.001$ & $0.702 \pm 0.002$ \\
\hline Hydration $^{\mathrm{d}}(\mathrm{g} / \mathrm{g})$ & $4.3 \pm 0.20$ & $0.90 \pm 0.05$ & $3.7 \pm 0.10$ & $3.7 \pm 0.10$ \\
\hline Viscosity increment $^{\mathrm{d}}$ & $2.73 \pm 0.11$ & $2.45 \pm 0.05$ & $2.71 \pm 0.05$ & $2.71 \pm 0.05$ \\
\hline Perrin value ${ }^{\mathrm{d}}$ & 0.998 & 1.001 & 0.998 & 0.998 \\
\hline $\mathrm{a} / \mathrm{b}^{\mathrm{e}}$ (if prolate) & $1.35 \pm 0.35$ & $0.97 \pm 0.03$ & $1.33 \pm 0.34$ & $1.33 \pm 0.34$ \\
\hline $\mathrm{a} / \mathrm{b}^{\mathrm{e}}$ (if oblate) & $1.38 \pm 0.38$ & $0.95 \pm 0.05$ & $1.36 \pm 0.36$ & $1.36 \pm 0.36$ \\
\hline
\end{tabular}

${ }^{a}$ Experimental data from SEC-TDA

${ }^{\mathrm{b}}$ Experimental data from QELS

${ }^{\mathrm{c}}$ Experimental data from AUC

${ }^{\mathrm{d}}$ Hydrodynamic parameters calculated as described in Material and Methods.

${ }^{\mathrm{e}}$ Calculated from viscosity increment and Perrin value 


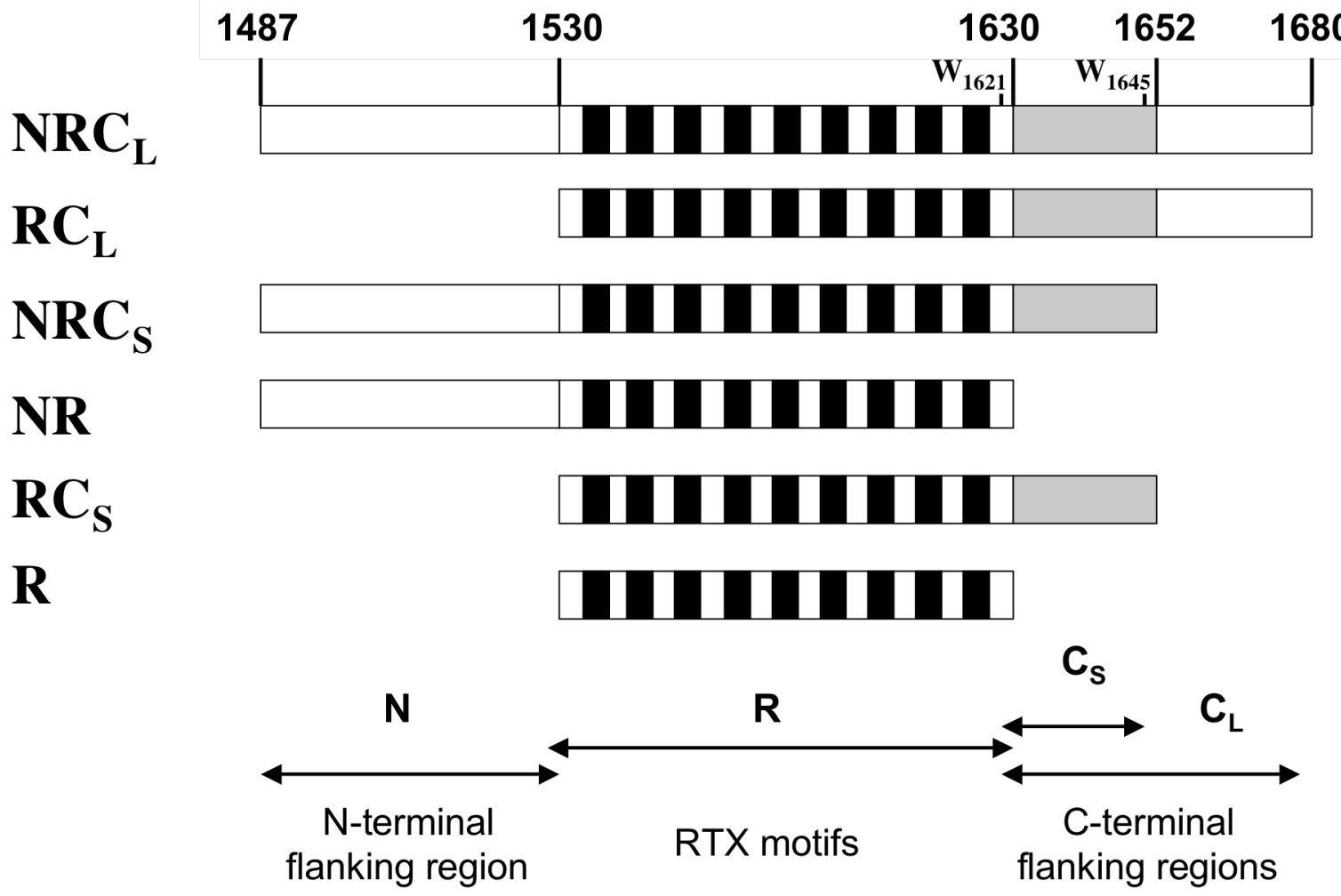

Figure 1 


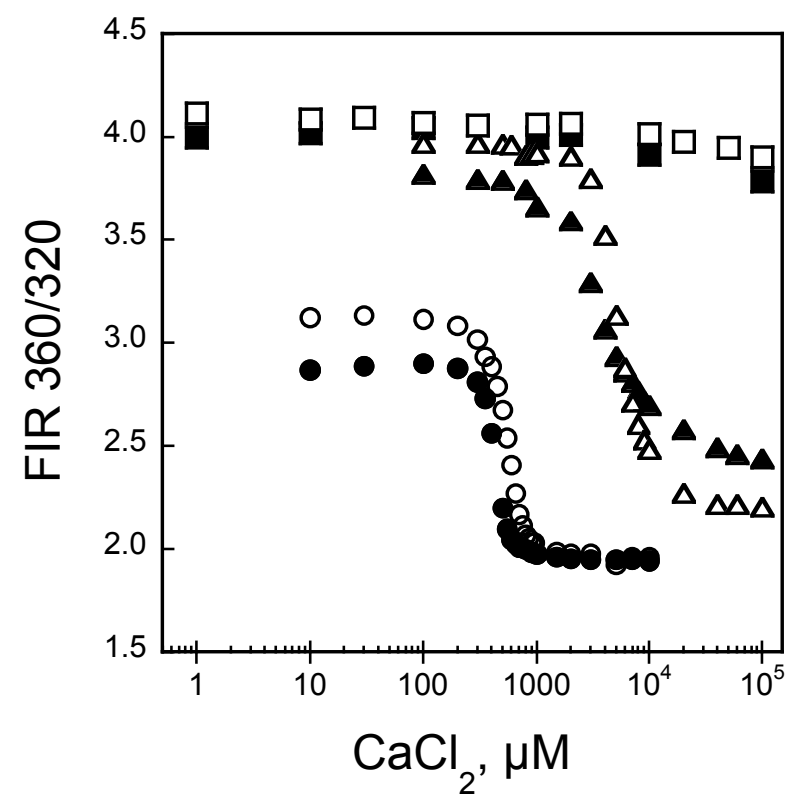

Figure 2 


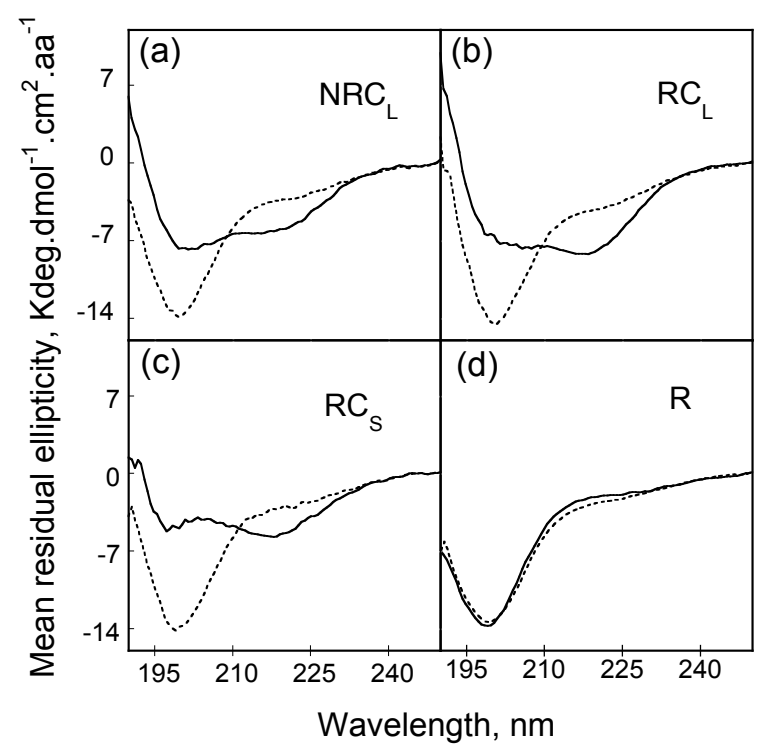

Figure 3 


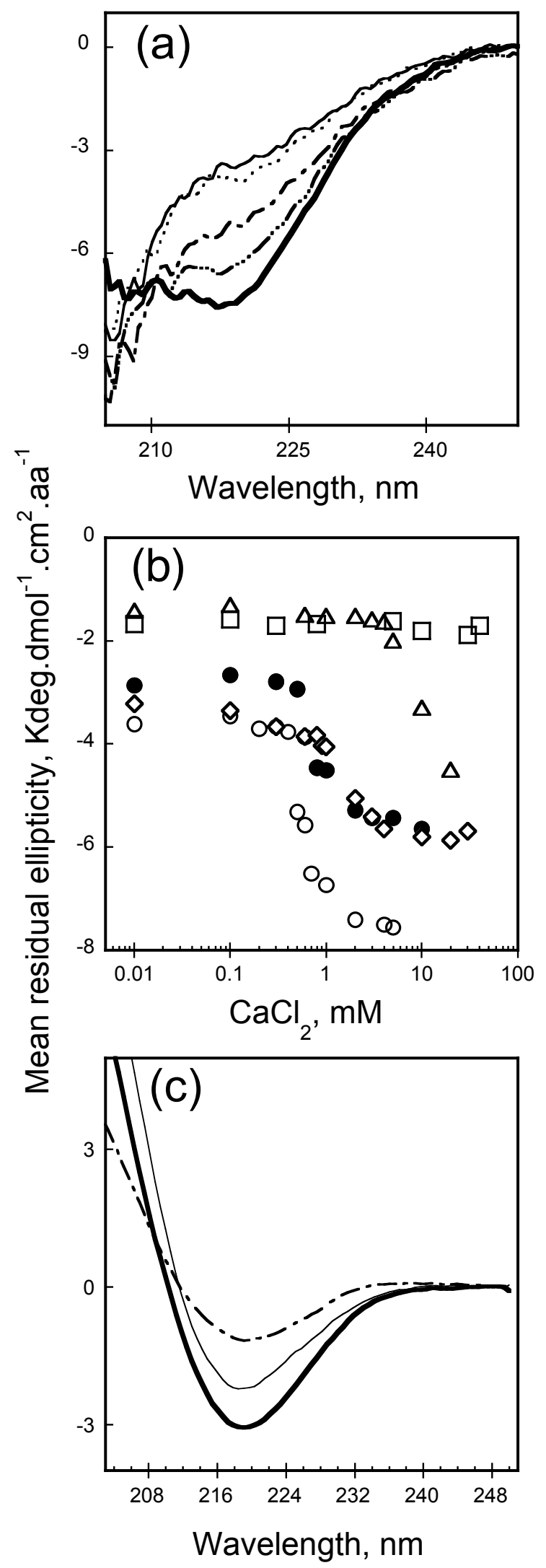

Figure 4 


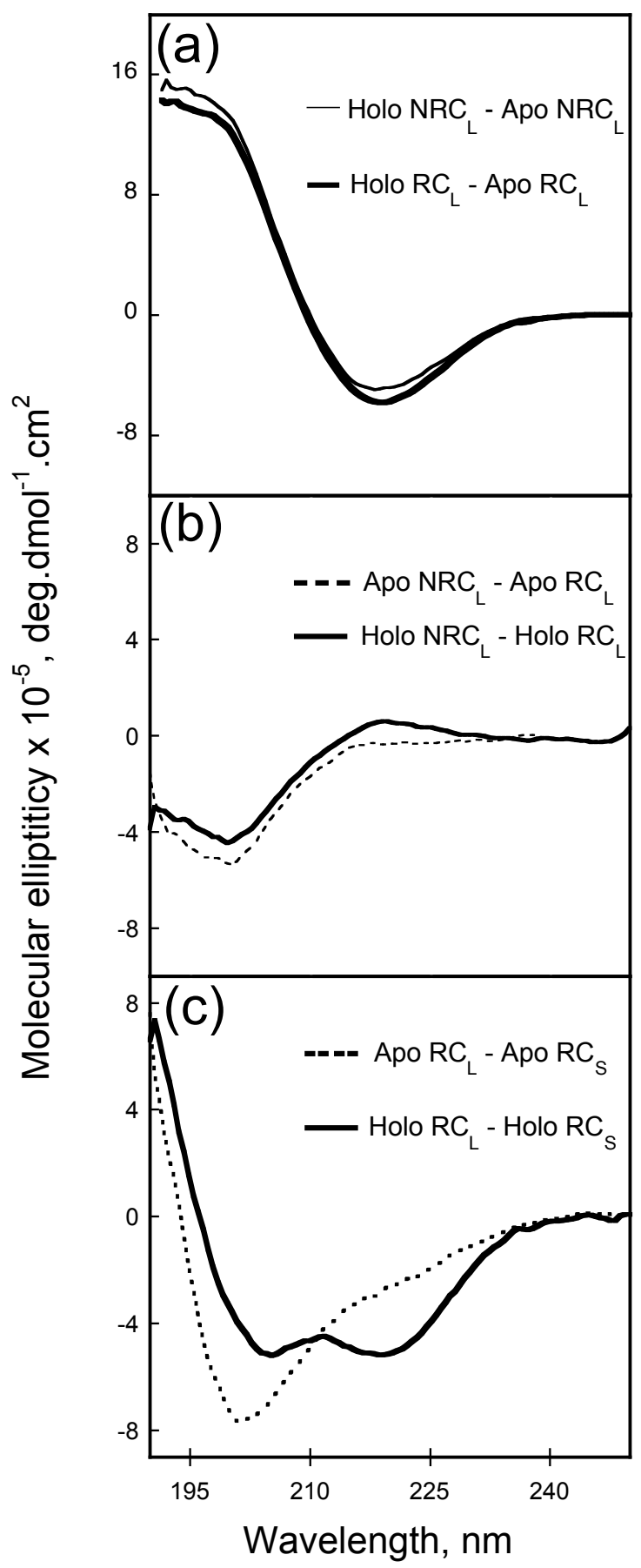

Figure 5 

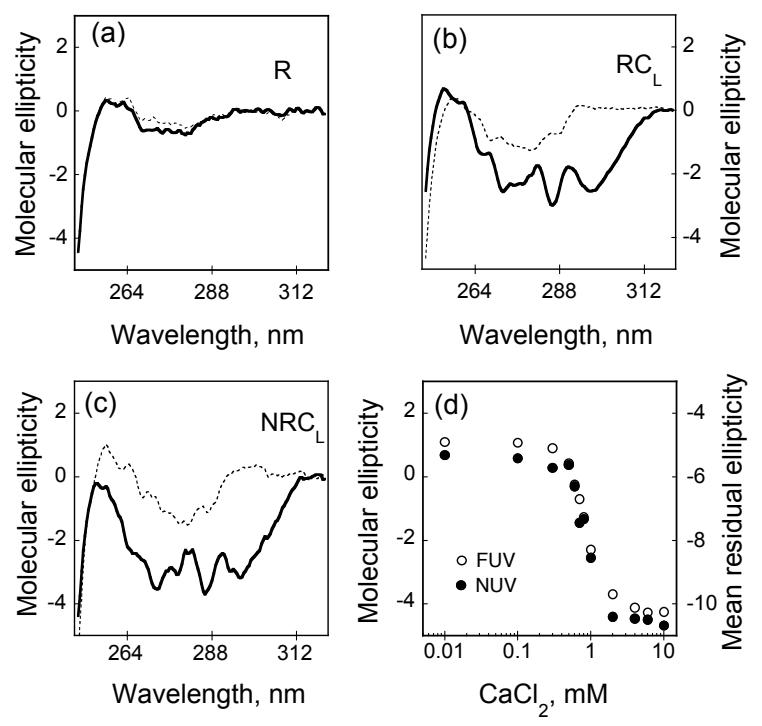

Figure 6 


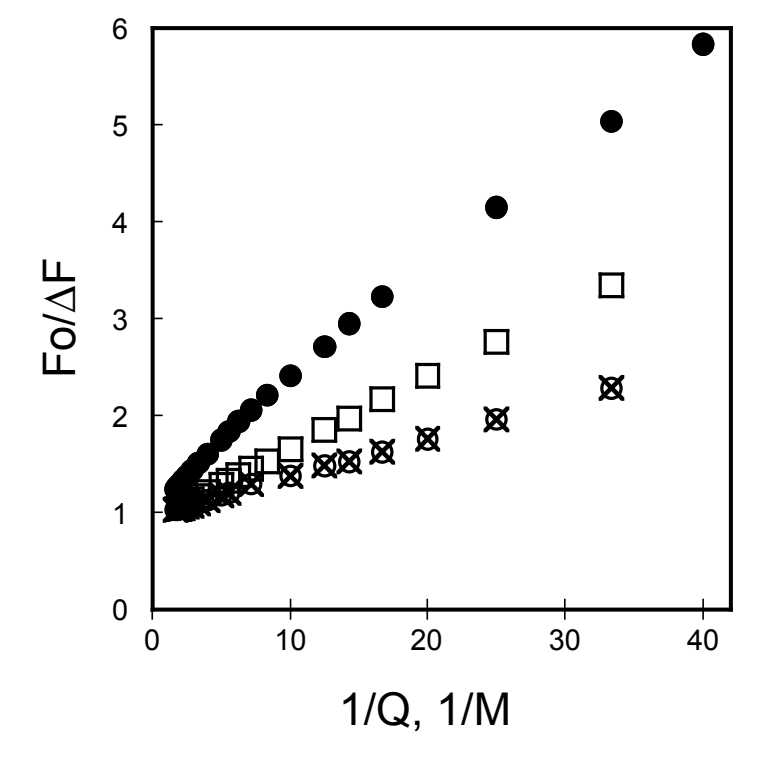

Figure 7

Figure 7

(2)

Figure

(1)

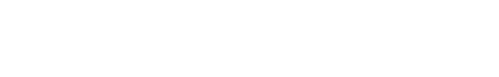

(1)

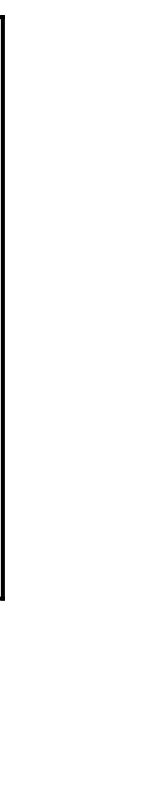

$\sqrt{2}$

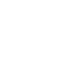

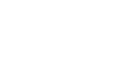

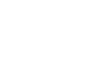

$\sqrt{2}$

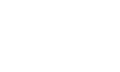

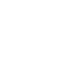

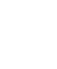

$+2$

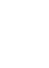

(n)

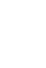

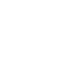

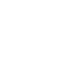

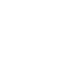

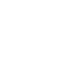
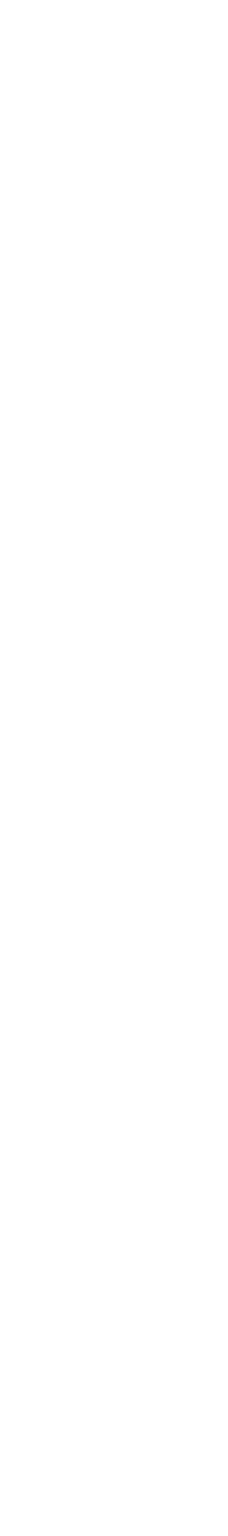

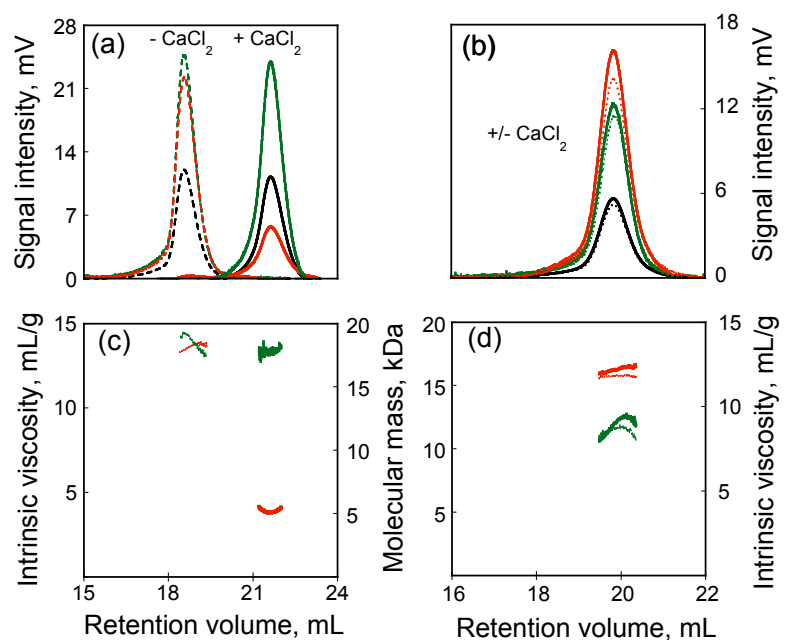

Figure 8 